\title{
WestVirginiaUniversity
}

THE RESEARCH REPOSITORY @ WVU

Graduate Theses, Dissertations, and Problem Reports

2008

\section{Cost model for a small glass manufacturing enterprise}

\author{
Swetha Gopisetti \\ West Virginia University
}

Follow this and additional works at: https://researchrepository.wvu.edu/etd

Part of the Engineering Science and Materials Commons, and the Materials Science and Engineering Commons

\section{Recommended Citation}

Gopisetti, Swetha, "Cost model for a small glass manufacturing enterprise" (2008). Graduate Theses, Dissertations, and Problem Reports. 3950.

https://researchrepository.wvu.edu/etd/3950

This Problem/Project Report is protected by copyright and/or related rights. It has been brought to you by the The Research Repository @WVU with permission from the rights-holder(s). You are free to use this Problem/Project Report in any way that is permitted by the copyright and related rights legislation that applies to your use. For other uses you must obtain permission from the rights-holder(s) directly, unless additional rights are indicated by a Creative Commons license in the record and/ or on the work itself. This Problem/Project Report has been accepted for inclusion in WVU Graduate Theses, Dissertations, and Problem Reports collection by an authorized administrator of The Research Repository @ WVU. For more information, please contact researchrepository@mail.wvu.edu. 


\title{
Cost Model for a Small Glass Manufacturing Enterprise
}

\author{
Swetha Gopisetti
}

Problem Report submitted to the College of Engineering and Mineral Resources at West Virginia University in partial fulfillment of the requirements for the degree of

\author{
Master of Science \\ in \\ Industrial Engineering
}
Robert. C. Creese, Ph.D., Chair
Rashpal Ahluwalia, Ph.D
Feng Yang, Ph.D

Department of Industrial and Management Systems Engineering Morgantown, West Virginia

Keywords: Glass manufacturing, Cost estimation, Marbles

Copyright 2008 Swetha Gopisetti 


\section{ABSTRACT \\ Cost Model for a Small Glass Manufacturing Enterprise \\ Swetha Gopisetti}

The cost model developed is for small, glass-manufacturing enterprises to help them determine their product costs. It estimates the direct cost in glass manufacturing such as material, labor and energy costs. The overhead costs were based on AACE recommended practices to determine product cost and selling price. The model was tested to estimate the costs in glass marble manufacturing. It determines the unit material cost of the product based on material mix ratio and material costs. The energy costs for the product were based on the batch processing time and gas consumption rate.

The model was analyzed to predict variations in prices of natural gas and raw materials. For an increase of natural gas cost from $\$ 5 / \mathrm{MCF}$ to $\$ 10 / \mathrm{MCF}$, the change in unit price of natural gas increased from $\$ 0.07 / \mathrm{lb}$ to $\$ 0.15 / \mathrm{lb}$. For every $\$ 1 / \mathrm{MCF}$ increase in cost of natural gas, the product cost increased by $\$ 0.02 /$ pound. For an increase of $\$ 0.10 / \mathrm{lb}$ in unit cullet cost, the unit material cost of the product increased by $\$ 0.08 / \mathrm{lb}$. 


\section{ACKNOWLEDGEMENT}

I would like to take this opportunity to thank my advisor, Dr. Robert C.Creese for his constant support, positive criticism, and encouragement throughout my period of study here. This work also would not have been possible without the guidance of my committee members, Dr. Rashpal Ahluwalia and Dr. Feng Yang, whose scientific suggestions helped me in my work and also to improve this problem report.

I am obligated to Marble King Industry, Paden City and Ms. Beri Fox, who helped me conduct my research. None of this work would have been possible without the support of the Department of Industrial Engineering and Management Systems, who helped me, complete my graduate program here.

I am grateful to all my fellow graduate students and my roommates for providing me a fun learning environment. I would like to especially thank Navya Reddy for her support in reviewing the report. Last but not the least, I am endlessly thankful to my parents, whose aspiration and guidance has helped me walk past all hurdles and achieve my goals. 


\section{TABLE OF CONTENTS}

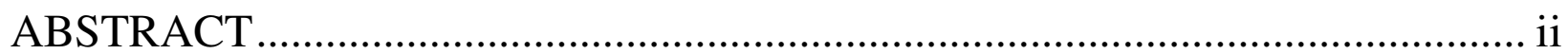

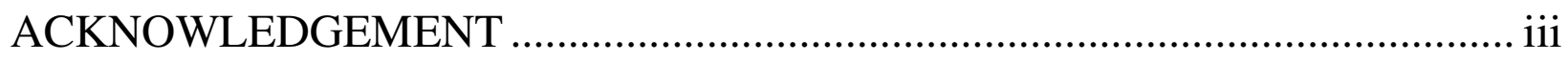

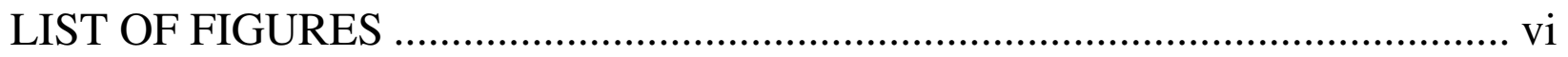

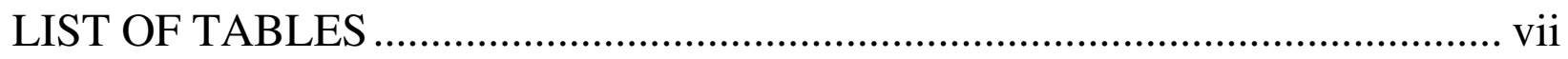

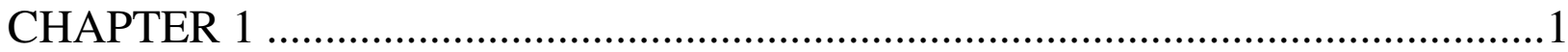

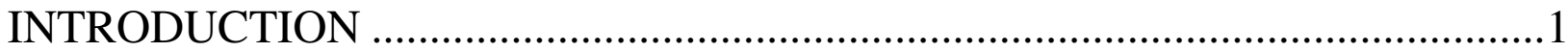

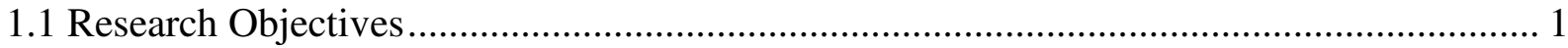

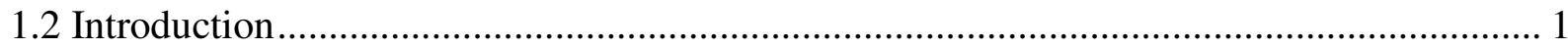

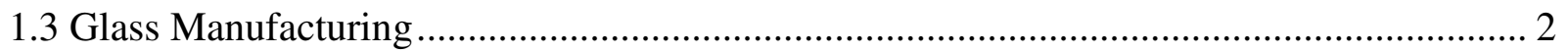

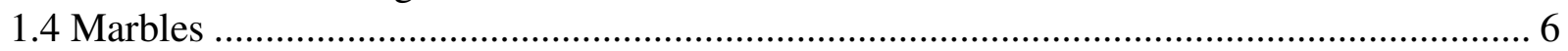

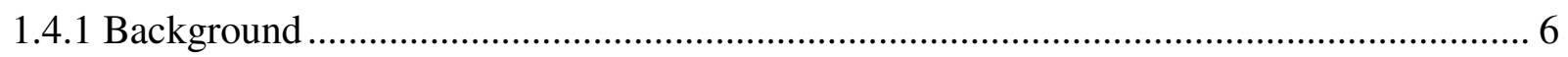

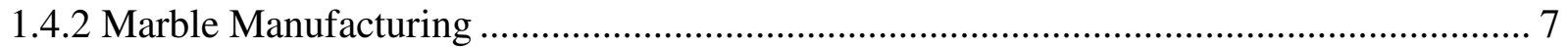

1.4.3 Glass Marble Manufacturing Process ............................................................................ 9

1.4.4 Criteria for determining Marble Value for Marble Collectors.......................................... 11

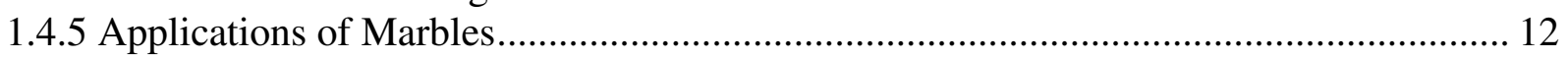

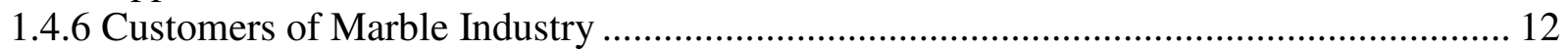

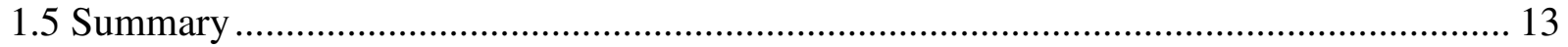

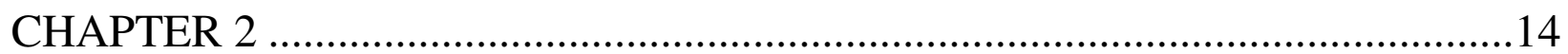

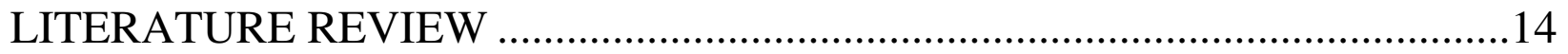

2.1 Methods of Cost Estimation....................................................................................... 14

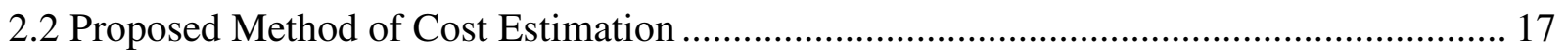

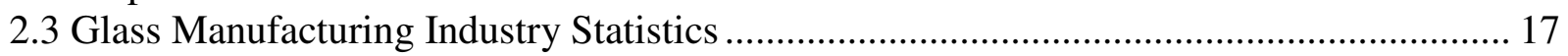

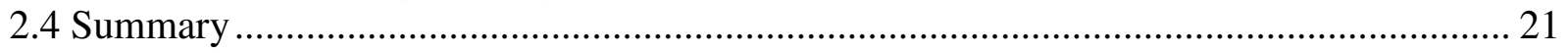

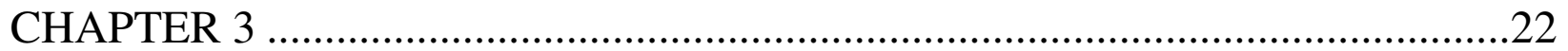

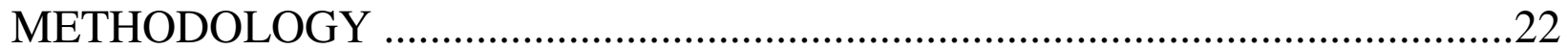

3.1 Model Input Data - Approach to Glass Industry ………….............................................. 22

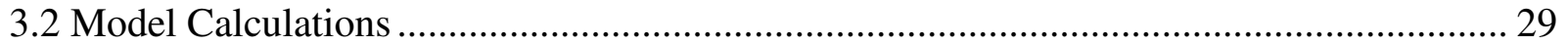

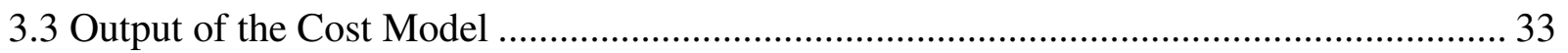

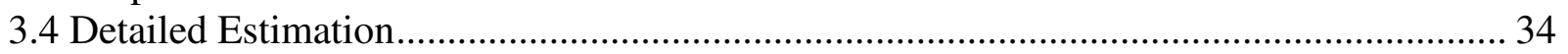

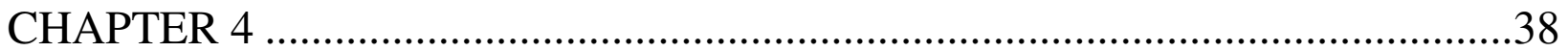

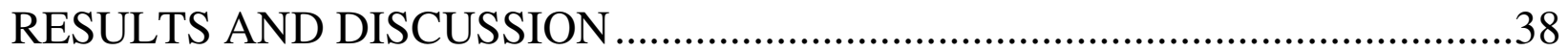

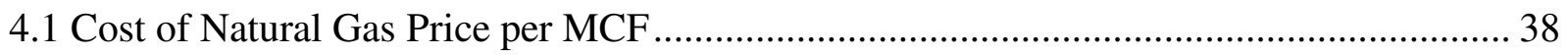


4.2 Unit Cullet Cost per Pound of Product Order ............................................................ 40

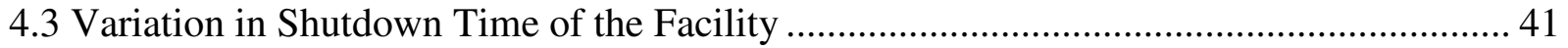

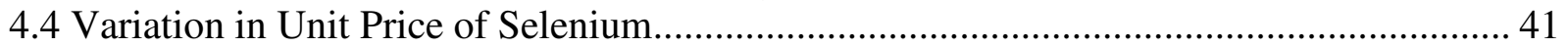

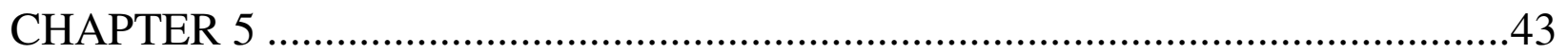

CONCLUSIONS ..............................................................................43

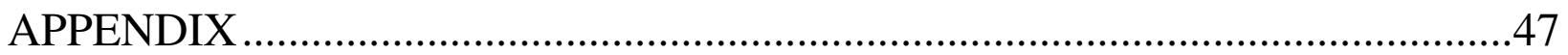

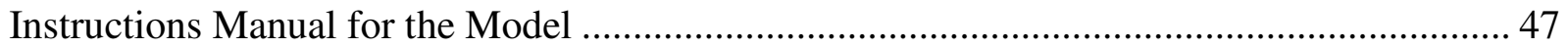




\section{LIST OF FIGURES}

Figure 1. Mixing and Furnace Charging into a Pot Furnace [6]................................................ 3

Figure 2. Tank Furnace Showing the Side Port for the Feed [18] ................................................ 4

Figure 3. Tank Furnace Showing the End Port for the Feed [18]............................................... 4

Figure 4. Front of Furnace with Rolling Machine Attached (Jabo Inc. 2003) [7]........................ 8

Figure 5. Melted Globs of Glass Being Formed into Marbles [7] ............................................. 9

Figure 6. Flow Chart for Glass Marble Manufacture. ............................................................. 10

Figure 7. Manufacturing Cost Components for Canadian Glass and Glass Manufacturing

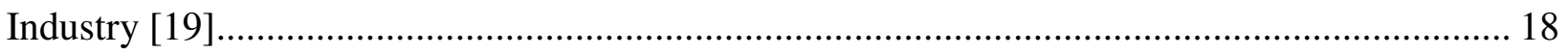

Figure 8. Variation of Canadian Glass Manufacturing Costs from 1993 - 2003 [19]................. 18

Figure 9. Screenshot of the Start of the Cost Model...................................................................... 22

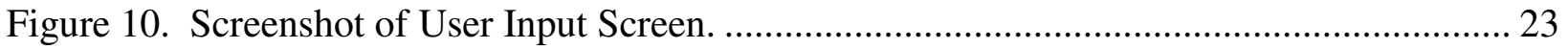

Figure 11. Screenshot of the Buttons for User Forms. .............................................................. 23

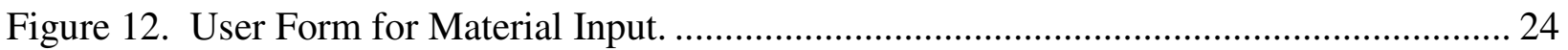

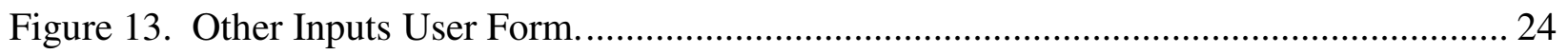

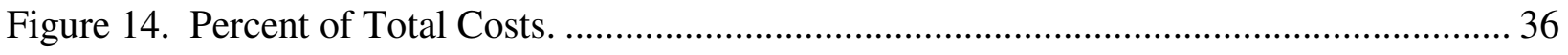

Figure 15. Unit Cost of Natural Gas and Total Gas Cost for the Product Order Vs Unit Cost of

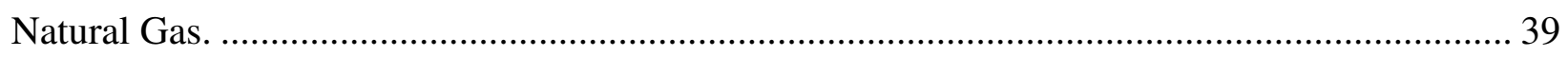

Figure 16. Variation in Total Unit Cost per Product Order with Change in Cullet Cost............. 40 


\section{LIST OF TABLES}

Table 1. Raw Material for the Production of Glass. .............................................................. 2

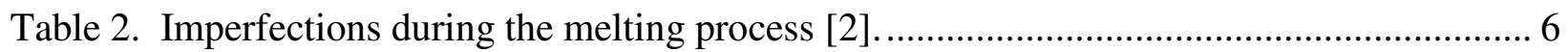

Table 3. Customers of Marble Industry. ............................................................................. 12

Table 4. Operating Parameters for Recycled Glass Processing System [20]. ......................... 20

Table 5. Line Production Items for Recycled Glass Processing [20]................................... 20

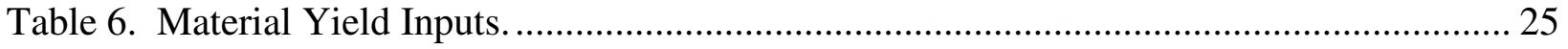

Table 7. Material Names, Mix Ratio and Unit cost ........................................................... 26

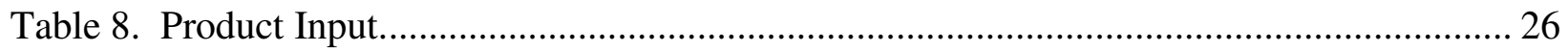

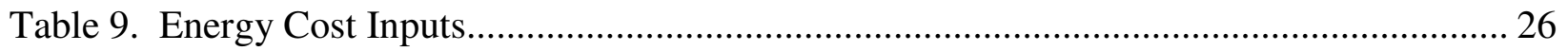

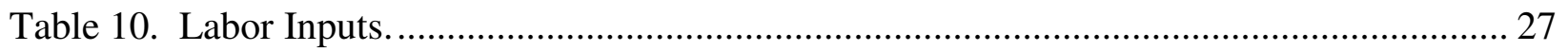

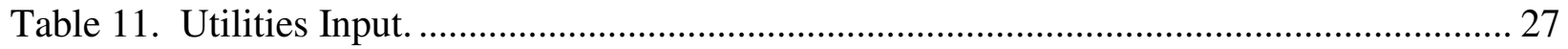

Table 12. Model Calculations for the Material Costs......................................................... 31

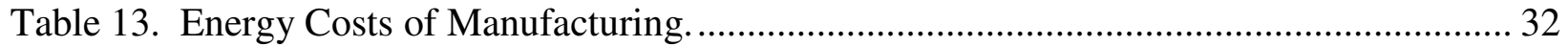

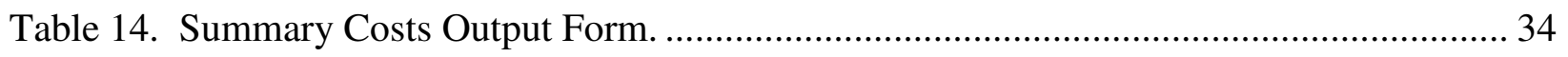

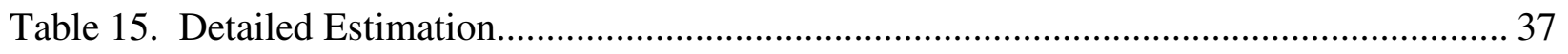

Table 16. Total Unit Cost /Pound of Natural Gas for Product Order. ...................................... 39

Table 17. Total Unit Material Cost of the Product Order.................................................... 40

Table 18. Total Unit Cost of Product with Change in Shutdown Period................................... 41

Table 19. Total Cost of Product Order with Variation in Unit Price of Selenium. .................... 42 


\section{CHAPTER 1}

\section{INTRODUCTION}

\subsection{Research Objectives}

The main objective of this research is to develop a cost estimation model using MSExcel@ for a small, glass manufacturing company. The objective is to allow the company to estimate the costs for manufacturing the product and the overheads associated with the product. The accuracy of the model compared with existing literature data and the specific facility is discussed. The project can be categorized into the following tasks:

1. Use of cost data of a facility for testing the accuracy of the model

2. Review of the glass manufacturing process

3. MS-Excel@ cost model for the glass production process

The research discusses in detail the steps in the production of glass. The cost model provides material cost, energy cost, labor cost, and selling expenses. It will let the organization have an idea of the costs that would incur when the customer orders a certain quantity of the product. The model is validated for a marble manufacturing facility with the cost data and the estimated costs were in accordance.

\subsection{Introduction}

Glass has been used for thousands of years. There are two kinds of glass: natural glass and man-made glass. The natural form of glass occurs when rocks high in silicates melt at high temperatures and cool before the molten mixture converts to crystalline structure. Volcanic glass is an example of naturally occurring glass. Man-made glass is a mixture of silica sand, soda, and lime. The additions of other materials, such as iron, cobalt, manganese, etc., give color to the 
glass. The varied usage of glass in day-to-day life, such as window panes, light bulbs, mirrors, plates, drinking glasses, and bowls has made glass manufacturing a significant division in the industrial sector. [1]

\subsection{Glass Manufacturing}

The manufacturing process of glass can be categorized into four major steps: batch mixing, furnace charging, melting and glass forming.

Batch mixing is the process of blending raw materials for the production of different glass products. The selection of raw materials depends on the type (color, texture) of product to be produced. The proportions of raw materials vary based on the desired color of the product. The raw materials mostly used in the production of glass are listed in Table1.

Table 1. Raw Material for the Production of Glass.

\begin{tabular}{|l|l|}
\hline 1. Cullet & 12. Borax \\
\hline 2. Red Cullet & 13. Manganese \\
\hline 3. Sand & 14. Black Copper Oxide \\
\hline 4. Soda Ash & 15. Potassium Bichromate \\
\hline 5. Feldspar & 16. Antimony \\
\hline 6. Potash & 17. Cobalt \\
\hline 7. Sodium Silicon Fluoride & 18. Cream of Tartar \\
\hline 8. Fluorspar & 19. Cadmium Mix \\
\hline 9. Zinc Oxide & 20. Selenium \\
\hline 10. Barium Carbonate & 21. Cadmium Sulphide \\
\hline 11. Mono Calcium Phosphate & 22. Limestone \\
\hline
\end{tabular}

The major proportion of raw material is cullet, and based on the desired color of the product, different proportions of other chemicals are used. The blended mixture is fed to the fired furnace for the purpose of melting.

Furnace charging is defined as the addition of mixtures to the furnace which can be done either in batches or continuously. Batch feeding is a discrete quantity fed at specific intervals to 
the furnace. It is mainly used for small furnaces with a production capacity of less than 10 tons per day. Continuous furnace feeding is the addition of the mixture at a constant rate with the help of screw, blanket, or push chargers. Chargers feed the mixture into the furnace, and the melting process begins. There are primarily two kinds of furnaces used by small, glass companies: pot furnaces and tank furnaces. The major difference between the pot and tank furnace lies in the construction of the furnace. Figure 1 shows the mixing and furnace charging into a pot furnace. Pot furnaces are generally used for colored glasses, and the crucible is covered. Feeding can be either batch or continuous, based on the desired product [2].

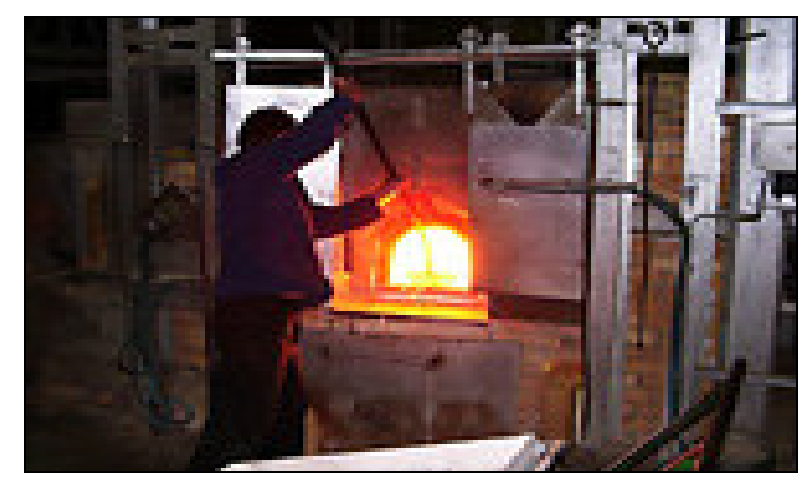

\section{Figure 1. Mixing and Furnace Charging into a Pot Furnace [6].}

Tank furnaces are built around refractory bricks. The firing of a tank furnace can be either across the length (end firing) or width of the furnace (cross firing). The batch mixture can also be fed either across the side port or the end port. Figures 2 and 3 show the side and end port tank furnaces respectively. 


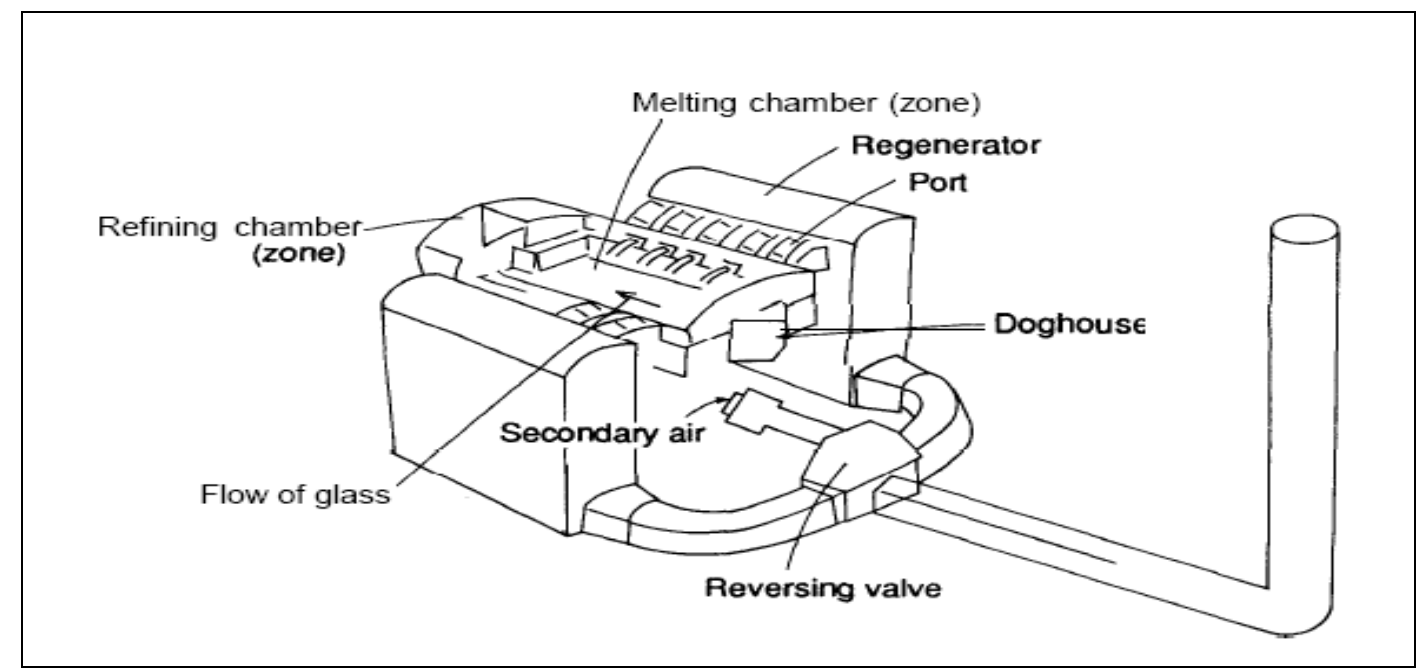

Figure 2. Tank Furnace Showing the Side Port for the Feed [18].

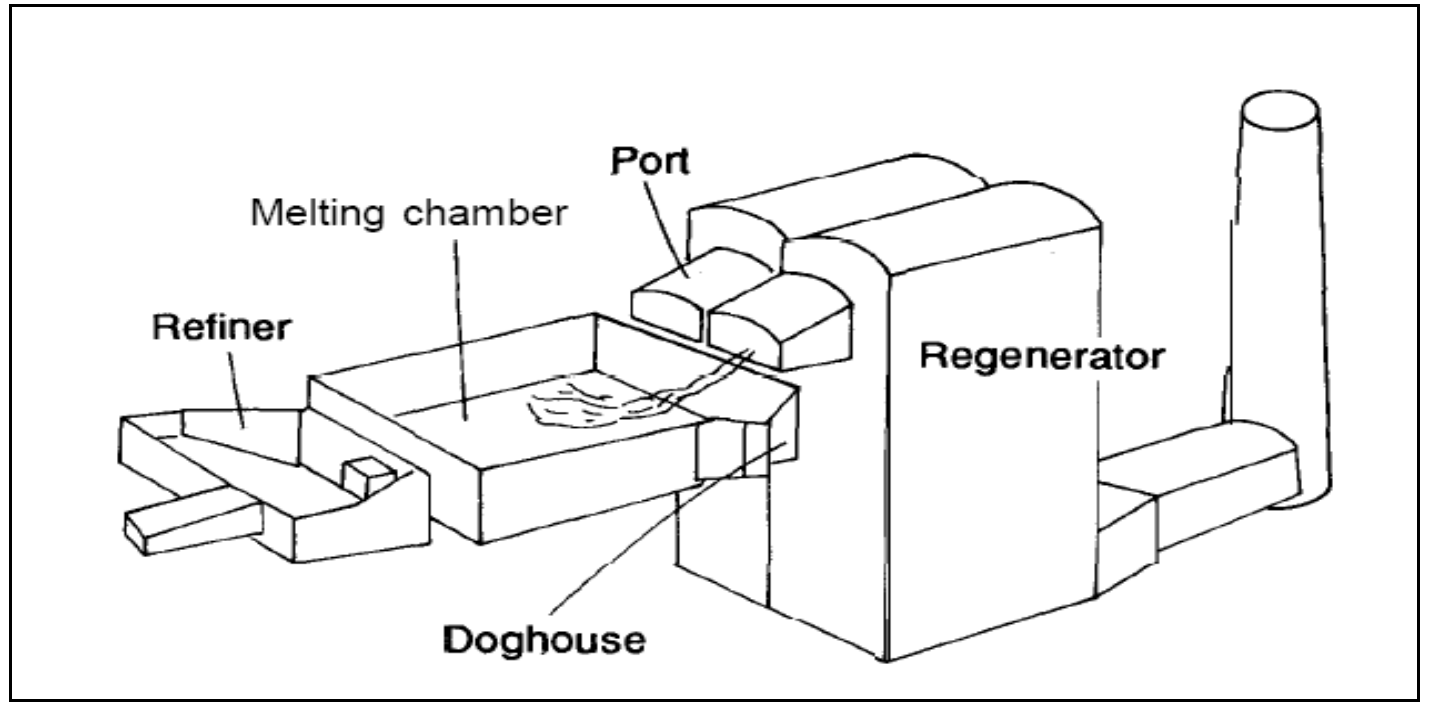

Figure 3. Tank Furnace Showing the End Port for the Feed [18].

The operating principles of the pot and tank furnaces are similar, with a batch mixture being fed to the furnace, melting the glass to the desired temperature, and cooling the molten glass to form the end product outside the furnace. The entire molten mixture is removed from the furnace before it is fed with another batch mixture. Pot and tank furnaces can be used for continuous production. The disadvantage with the two furnaces is the wait time for the next 
batch, since it requires time for the current batch to heat to the desired temperature. A constant heating rate is usually maintained for all the batches of the glass. [4]

The step after feeding the batch into the furnace in glass production is the melting process, comprised of melting, fining, homogenizing, and heat conditioning. Melting of the glass starts when the raw materials are introduced into the fired furnace. As the furnace is heated up, water evaporates from the mixture, and the constituents begin to transform to liquid phase. Sometimes the raw materials are sprayed with water to reduce dust. Gases such as $\mathrm{CO}_{2}, \mathrm{SO}_{2}$, and $\mathrm{SO}_{3}$ are released during the melting process of the glass, which necessitates homogenization. The process of fining is extended until all the bubbles are removed from the surface of the glass. It is not necessary that all four processes occur in a sequential order, and they may overlap. When the melting and fining are entirely completed, the homogenizing phase starts, since it is ready to form the desired product. The time required for homogenization depends on the particle size of the batch materials and the temperature. [4]

Heat conditioning is the process initiated when the melted glass is ready to form the final product. It builds uniformity of glass temperature at the forming end of the furnace. The time needed for this is based on the volume of the glass in forming the final product, temperature of the end product, and flow rate of the glass during the forming process.

The end process of glass production is the forming that happens outside the furnace. There are different kinds of glass-forming processes. Some of the glass forming processes are hand blowing, molding, floating, and glass fiber production. The quality of the glass after forming is related to the melting process. The imperfections that may happen during the melting process are listed in Table 2. 
Table 2. Imperfections during the melting process [2].

\begin{tabular}{|c|c|}
\hline Problem & Effect \\
\hline Insufficient refining & Seeds or bubbles within the glass \\
\hline Insufficient homogenizing & Areas of inconsistent glass \\
\hline Inconsistent batch size & Areas of inconsistent glass \\
\hline Atmospheric pollution infiltration & Discoloration of glass \\
\hline Poor temperature control & All of the above \\
\hline
\end{tabular}

Glass blowing is a traditional technique for forming a glass product. The process involves accumulation of glass by rotating the end of a hollow iron tube called the blow pipe. The gathered glass is cooled to about $1000^{\circ} \mathrm{C}$ and is rolled on an iron slab. It is elongated, reheated, and then air blown to form the desired article. This is laid on a wooden or iron mold which is kept wet by water, and the glass is blown into final shape in the interior of the mold. In the process of blowing, the hollow pipe is rotated continuously to prevent any imperfections in the mold. The major method of forming glass articles for almost 2000 years was glass blowing by hand. In the $19^{\text {th }}$ century glass blowing by compressed air came into existence and in the later $20^{\text {th }}$ century, the mechanization or automation of the process was developed. The automatic process involves feeding the raw material mix into the furnace, where it is heated to $1500^{\circ} \mathrm{C}$. [16] Marble manufacturing is an example of the usage of the automatic process.

\subsection{Marbles}

\subsubsection{Background}

Marbles are small, spherical objects made from glass and used for children's games, as pebbles in flower vases, or as fomenters inside a can of spray paint. Ancient marbles were made 
out of clay and stone. It is supposed that the ancient games played with marbles subsequently led to sports now known as billiards, bowling, and pinball [7]. The origin of glass marbles was either in Germany or Venice since both countries had developed glass blowing industries in the nineteenth century. In the late 1800 s, marbles were manufactured using glass in the United States. In 1905, Martin Frederick Christensen was awarded a patent for the invention of a marble-making machine. The company produced approximately 10,000 marbles a day. The start of World War I caused a shortage of natural gas, and Christensen's operations came to an end. In 1920, the Akro Agate Company improved the marble-making machine and became the major marble manufacturer. At the time of World War II, the widespread use of plastic reduced the company's market. The Akro Agate Company ceased its production in 1949, though it continued its sales until 1951 with its surplus production. Marbles vary in size from about 0.5 inches to less than $1 \frac{1}{2}$ inches in diameter and are available in different shades of colors. [19] The demand for marbles reduced as children's interest inclined toward more sophisticated toys. Many of the marble manufacturers have shifted their business to other glass related products, such as glass bottles and glass containers. There were only two marble manufacturing companies in the United States till 2006: Jabo Inc. in Ohio and Marble King in West Virginia [15]. Jabo Inc. in Ohio ceased its operations in 2007.

\subsubsection{Marble Manufacturing}

The batch mixture for marbles consists of silica sand, soda lime (calcium hydroxide and potassium or sodium hydroxide), cullet, and other constituents for pigmentation. Soda lime absorbs carbon dioxide and acts as a drying agent. Silica (sand) is essentially a white or colorless insoluble solid found in flint, quartz, and other rocks. Cullet is the broken glass or scrap glass used for re-melting purposes. [7] 
Initially, silica sand, cullet, and other raw materials are fed into a large furnace, where the mixture is heated to approximately $2300^{\circ} \mathrm{F}$ to melt the constituents. [9] The molten mixture is moved out of the furnace into the fore hearth, where melted colored glass is injected with high velocity from the top of the furnace to get the streak appearance inside the marble. The speed and force of injection decides the final design of the marble. Some of the constituents for different colors of the marbles are: [18]

- A green marble contains iron oxide.

- A blue marble contains cobalt.

- A purple marble contains manganese.

- A greenish - yellow marble contains uranium oxide.

Figure 4 shows the attachement of a rolling machine to the furnace.

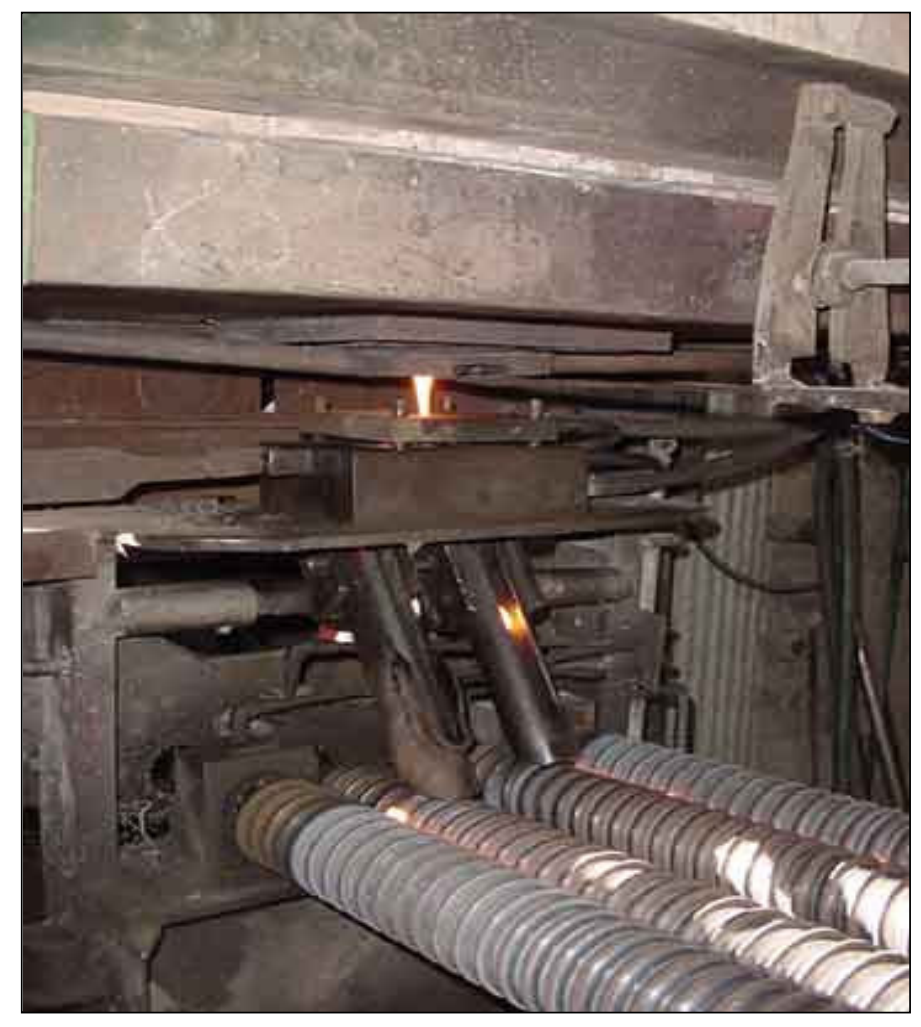

Figure 4. Front of Furnace with Rolling Machine Attached (Jabo Inc. 2003) [7]. 
Finally, the molten glass is cut by scissors and rolled on the rotary device to form globs of glass. Figure 5 shows the globs of glass on the rotary machine being formed into marbles. The spherical marbles are simultaneously cooled and formed into their final shape while traveling along the roll. After cooling, the marbles are automatically sorted by size and sent for inspection and packing. Marbles with defects are sent back for re-melting or used as fomenters.

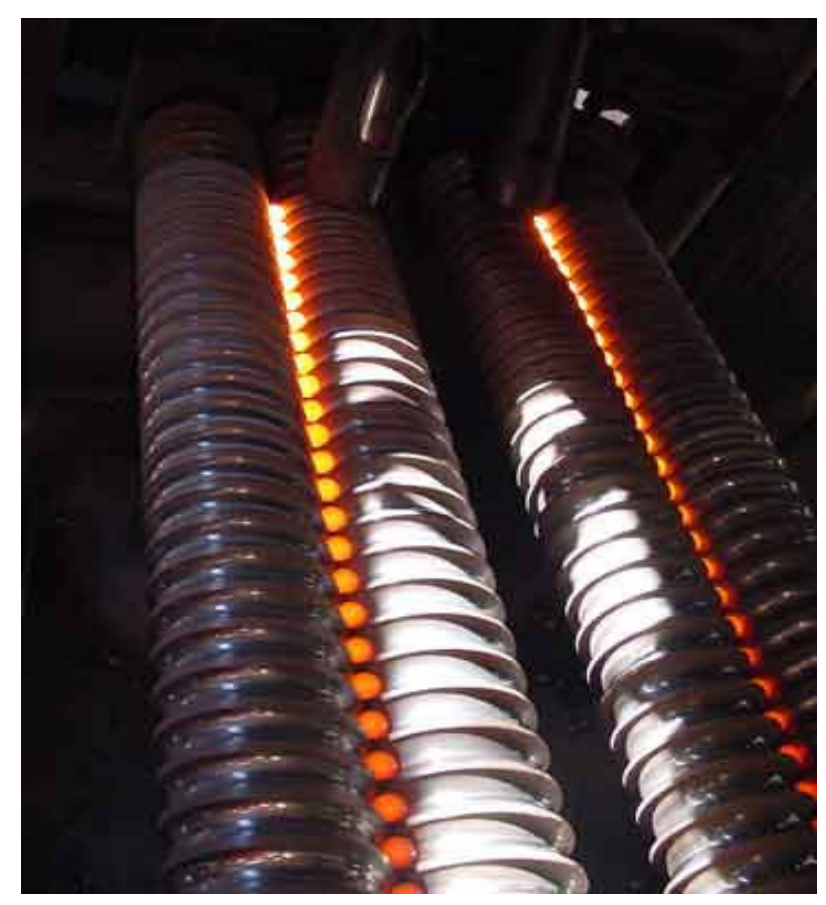

Figure 5. Melted Globs of Glass Being Formed into Marbles [7].

\subsubsection{Glass Marble Manufacturing Process}

The flow process of marble manufacturing is illustrated in Figure 6 . The first step in the process involves the mixture of silica sand, cullet, and other raw materials to be fed into the furnace. The natural-gas-fired furnace heats the mixture to around $2300^{\circ} \mathrm{F}$. In the process of melting the glass, some materials are oxidized as slag or converted to exhaust gases, and the quantity of raw materials that forms the glass is reduced. In the fore hearth of the furnace, the melted glass is injected on the top with colored glass to give streaks to the marbles. 
The molten mixture is cut into globs of glass and released onto a rotary device, where the sizing of the marble is carried out by adjusting the size of the rollers. The process of dropping the globs of glass onto the rolling machine causes some breakage of the marbles.

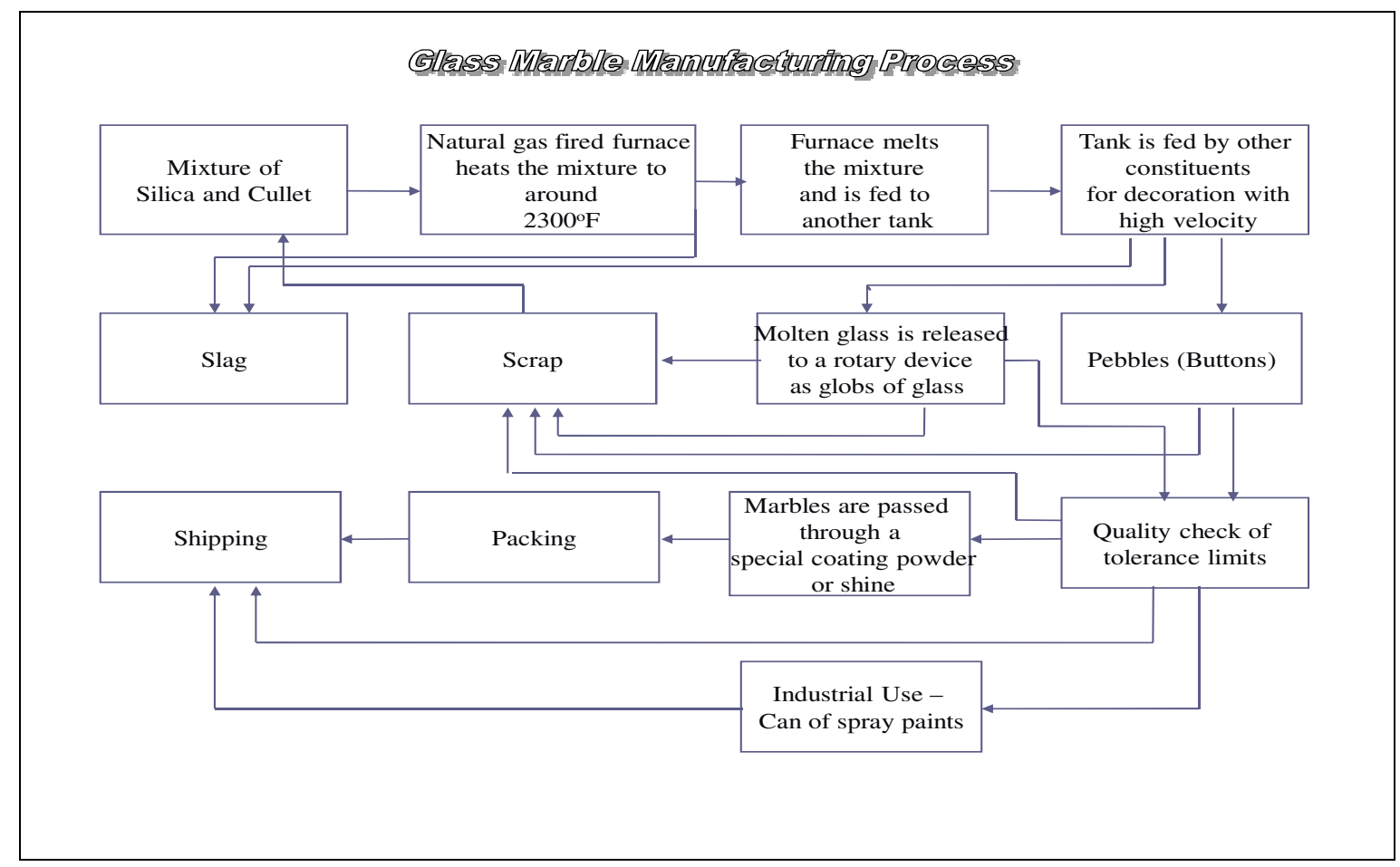

Figure 6. Flow Chart for Glass Marble Manufacture.

Pebbles are made by dropping the globs of glass onto a flat circular table and cooled by rotating the table. The pebbles have a flat surface. The pebbles or formed marbles are sent for quality check to see if the product is within the tolerance limit or has surface defects. The first size check of the marbles is carried out when marbles are dropped from the rollers into a sizing bin. Marbles that do not meet the quality requirement are considered to be scrap. These scrap marbles may be used for industrial purposes, such as a fomenter in a can of spray paint. Some marbles are passed through a special coating powder to give a shiny appearance for special orders. Finished marbles are packed and prepared for shipping to the customer. Scrap marbles 
are recycled using a crushing machine and utilized as a raw material feed (cullet) to manufacture new marbles.

\subsubsection{Criteria for determining Marble Value for Marble Collectors}

There are four factors that determine the value of a marble: 1.Type, 2.Condition, 3. Size and 4. Eye appeal.

1. Type: A crucial factor in determining the value is the rareness of the type of marble. A marble can be of lesser price even though it is rare because it is not known to many of the marble collectors. In those instances, it can be said that the rarity and price are not directly related.

2. Condition: Another major factor that determines the value is the condition of the marble. The four categories of the descriptive grading system defined by Marble Collectors Society of America are: Mint, Near Mint, Good, and Collectible. The grading system is based on the defects seen on the marble. A numerical grading system is also developed on a scale of 1-10.

1. Mint : No damage or repair over the marble (10.0-9.0)

2. Near Mint : A small amount of visible wear ( less than half of the overall surface, 8.98.0)

3. Good : Significant wear (over half of the overall surface, 7.9-7.0)

4. Collectible: Deeper damages; otherwise known as "Poor Marbles". (6.9 -0.0)

3. Size: Another factor is the diameter measured in inches or millimeters. Marble manufacturers use sieve system of measuring. Hand-made marbles are produced in sizes less than $1 \frac{1}{2}$ inch in diameter, whereas machine-made marbles are produced in diameters of $1 / 2$ to $3 / 4$ inch. Marble tournament regulations set the size of the shooter marbles to be between $1 / 2$ inch and $3 / 4$ inch, and the target marble is $5 / 8$ inch diameter. 
4. Eye appeal: The final determinant for the value of a marble is eye appeal. It is attributed to the brightness of colors and the design of the marble. It varies based on individual perception, and the condition of the marble defined by the grading system. Attractive colors and complex designs have higher prices. These factors vary between collectors. [8]

\subsubsection{Applications of Marbles}

Marbles are used in games such as Chinese checkers, Pokemon, and 32 swirl board. Glass pebbles are used for decoration purposes in a flower-vase, night lights, and as gem marbles at the bottom of a candle bowl. There are many industrial uses for marbles including:

(1) fomenters/agitators in a can of spray paint; (2) constituents that can be dropped in to oil wells to raise the pressure to facilitate increase in production (3) ballot box marbles; (4) for ease in moving the coffin box in the funeral industry; and (5) for capping of soda bottles in the soft drinks industry. [9] Marbles have importance in playing games and tournaments. The United States National Marble Tournament started in the early 1920s and occurs annually in June in Wildwood, New Jersey. There are more than 1,200 games played in the four-day tournament.

\subsubsection{Customers of Marble Industry}

The majority of the customers for marbles are the toy and game companies. Some of the customers of the marble industry and their games are listed in Table 3.

Table 3. Customers of Marble Industry.

\begin{tabular}{|l|l|}
\hline \multicolumn{1}{|c|}{ Manufacturing Company } & \multicolumn{1}{c|}{ Game } \\
\hline Wizards of the Coast & Pokemon (Thunderstorm Gift Box) \\
\hline Milton Bradley & Hungry Hippos \\
\hline Mattel & Ker Plunk \\
\hline Pavillion & Marble Game Set \\
\hline Tyco & Ker Plunk \\
\hline Broadway Toys & Goin Nuts \\
\hline
\end{tabular}




\subsection{Summary}

The steps in the manufacturing process of glass are batch mixing, furnace charging, melting and glass forming. The majority of the customers in the marble industry are toy and game companies. The two major types of furnaces used are pot and tank furnaces. The glass marble manufacturing process was presented in detail. The criteria for determining the value of marbles as collectibles was discussed. Examples of companies and their customers that use marbles in their games were listed. The majority of the customers are toy and game companies. 


\section{CHAPTER 2}

\section{LITERATURE REVIEW}

A systematic literature search was conducted to locate references of manufacturing cost estimation methods and manufacturing costs related to the glass industry. During the research, various databases were queried, including the West Virginia University Libraries and the World Wide Web for material related to glass and marble manufacturing. The results of this search were a major assistance toward the development of this report. The results were arranged into the categories of: glass manufacturing and marble manufacturing, methods of cost estimation, glass manufacturing industry statistics, and cost models for recycled glass.

\subsection{Methods of Cost Estimation}

Costing is defined as a process of tracking and analyzing costs associated with the products or activities of an organization. It is used by industry in decision making to reduce the costs and increase profitability. Initially, cost estimation methods mainly focused on variable costs because they varied directly with the production levels. The amount of raw materials, labor and the efficiency required to run a factory were in direct proportion to production. The estimator would sum the total variable costs and use these for decision making. After a certain period, managers gave more importance to fixed costs that would not change with the production quantity. Some of the fixed costs include depreciation of plant and equipment, and costs of different departments such as administration, maintenance, etc. It is necessary for a manager to understand that fixed costs must be recovered. Estimation can be done by at least three approaches: (1) Standard cost estimation, (2) Activity cost estimation, and (3) Marginal costing. 
The standard cost estimation method was studied and developed to aid the management in decision making. Standard costing is a measure to analyze the costs before production with an estimate of the quantity, hours required for production, setup time, and labor. In standard cost estimation, overheads are attributed to the product. The overheads might be the administrative employees, indirect materials, and machine hours. Performance of the employees, utilization of the equipment and machines and the amount of overhead absorbed for production can be measured using standard cost estimation. The organization must keep track of actual costs for each production step while measuring the performances in order to have control over the production costs [13]. The documentation of actual costs helps the managers to exercise the overhead on the unit cost of the product over that period and also facilitates the consideration of inventory costs. The actual costs will be different from the standard costs. Some reasons for variation could be the material price changes, difference in actual production time, or changes in the production quantity. The important aspect of standard estimation is the variance analysis, which tells the difference between the actual and standard costs (material variation, labor cost variation, and volume variation).

Activity-based cost (ABC) estimation assigns costs to the products based on the resources each activity consumes. In the first step in activity-based costing, the system identifies the activities for making a product and the initiations that create activities. For example, the activity of setting up a machine triggers the consumption of an operator and a machine. The difference between activity costing and standard costing lies in the allocation of overheads to the products. The assumptions of activity-based costing are: (1) It assumes that the product incurs indirect costs by requiring resource-consuming activities, such as warehousing, scheduling, inspection, production setups, and so on. (2) Products create the need for the indirect activities and hence 
the indirect costs are based on the activities they cause. $\mathrm{ABC}$ assigns indirect costs to the product based on the number of activities it requires and the cost per activity is obtained by dividing the cost of each activity by the total number of activities performed [21]. Administrative costs cannot be associated with any particular product produced and remain the same irrespective of the cost of the activity. Overhead costs are calculated based on the indirect costs the activity consumes. They drive the managers for local efficiency measurements to optimize the use of every activity in the production process. The companies can use the activity cost data to see the focus for operational improvements [14]. ABC allows for the prioritization of cost-management efforts by providing the summary costs of organizational activities.

Marginal cost estimation is mainly applied for short term decision making that determines the contribution per product. Contribution may be defined as the profit before the recovery of fixed costs. The contribution is the difference between the sales and marginal cost. Marginal cost is the summation of direct labor, direct material, direct expenses, and variable overheads. The objective is to maximize the contribution per unit. If constraints exist on resources, then managerial costing would aim at the maximization of the contribution per unit of the constrained resource. Marginal costing mainly shows the increase or decrease in profits with the change in the volume of output i.e., in addition to the existing level of production.

The cost estimation for a manufacturing process is dependent upon the actual time for each manufacturing step to which all non-value allowances, overheads ( transportation, idle time) etc., are added. In each production step, all task lists are required for building a good cost estimate. The task lists include all the steps in a production step to get the final product of the corresponding production step. Accurate data is needed if the cost estimate is to be reliable. The cost estimation for a certain product must be filed and documented to provide detailed analysis 
of the causes of variation between actual and estimated costs. Non-value added allowances vary between batches of product manufacture. It is a requisite to review and compare the actual and estimated costs to interpret the causes for the variations and to study the trends. There is a possibility that the estimate is correct but some element of the operation has caused a difference (use of unskilled operators) [11].

\subsection{Proposed Method of Cost Estimation}

The proposed method of cost estimation for determining unit cost of the glass product is standard cost estimation. The model is considered for a small manufacturing enterprise to estimate the standard cost of all the manufacturing operations in the process flow. The purpose of cost estimation model is to asses the unit cost of the product by calculating the cost of each manufacturing operation. The manufacturing operations involved were mix of raw materials, furnace charge of raw materials where they are heated to high temperatures and converted to molten glass, automatic cutting of the molten glass to globs and dropping them onto the rollers or onto the circular table, quality inspection, packing, and shipping. The model estimates the overhead expenses for the manufacturing process, such as administration costs, indirect labor costs, utilities, shipping, and taxes. The cost should be compared to the actual cost to see if there is any deviation from time to time.

\subsection{Glass Manufacturing Industry Statistics}

The Canadian Industry Statistics provided information on glass and glass product manufacturing costs and the varying natural gas prices used for the furnace between 1993 and 2004. The industries with employees in manufacturing and sales of manufactured goods greater than $\$ 30,000$ Canadian dollars as principal establishments were considered for the statistics. The major manufacturing costs were divided into cost of materials and supplies, cost of fuel and 
electricity, and salaries. Materials and supplies costs and fuel costs are susceptible to any price changes in the glass and glass product manufacturing industry. The distribution of the manufacturing costs in the year 2003 for glass and glass product manufacturing principal establishments in Canada is shown in Figure 7 [19].

The cost of materials and supplies increased from $\$ 579.6$ million in 1994 to $\$ 870.5$ million in 2003 for the manufacturing activities at a compound annual growth rate of $4.6 \%$. The variation of the costs from 1994 to 2003 is shown in Figure 8 [19]. The cost of fuel, electricity, and the production wages in variation with material costs is also shown.

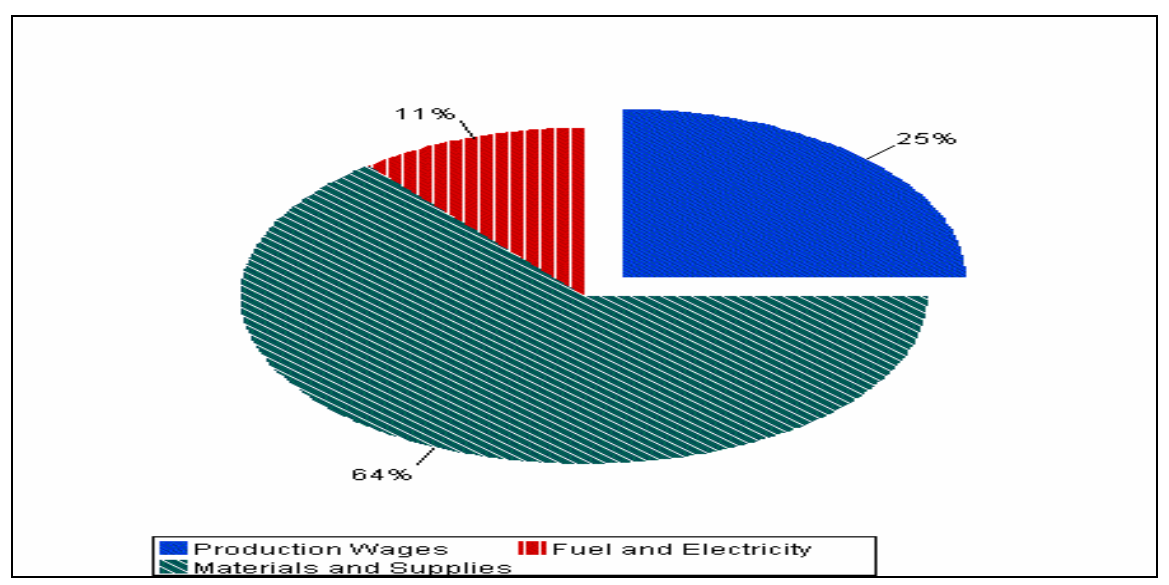

Figure 7. Manufacturing Cost Components for Canadian Glass and Glass Manufacturing Industry [19].

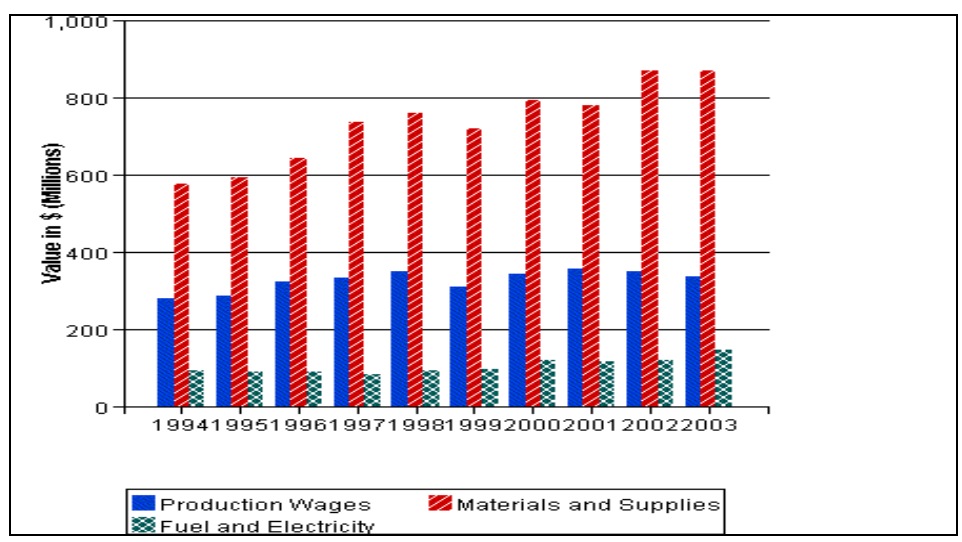

Figure 8. Variation of Canadian Glass Manufacturing Costs from 1993 - 2003 [19]. 
In order to reduce the material costs, many glass manufacturing industries in the United States use recycled glass as the raw material. The scrap obtained from the manufacturing process of glass can be processed and used as recycled glass (cullet). The Clear Washington Center [20] describes the best practice in glass recycling that involves a logical sequence of steps to develop an economic model for glass processing:

- Determine the volume of the local recycled glass available.

- Determine the specifications to which glass needs to be processed. There are some smallscale equipments available in the markets that have the capability to pulverize the glass. The finer the glass, the higher the potential value in the market.

- Determine the part in the equipment that will attain the gradation required. The survey from equipment manufactures and existing users helps in finding the better equipment.

- Build a cost model for processing, and compare the model with the current potential values and available volumes of glass.

The major costs that are required to be considered are capital costs, production costs, selling costs, general, and administrative costs. Capital costs include fixed equipment costs and the site costs. The pulverizing machine for small-scale operations ( 1 to 5 tons per hour) may costs between $\$ 10,000$ and $\$ 40,000$. Production costs include the costs of labor, building and equipment rental, utilities, gasoline, oil and supplies, and cost of debris and dust removal. Selling costs, general, and administration costs include management costs, expenses, insurance, taxes and commissions. The cost and time required for marketing should be measured. The example spreadsheet [20] for the glass recycling processing is given in Table 4 that shows the 
operating parameters for glass recycling. Table 5 shows the line production items that are typically required for a small scale operation of recycled glass.

Table 4. Operating Parameters for Recycled Glass Processing System [20].

\begin{tabular}{|l|l|}
\hline \multicolumn{2}{|c|}{ Economic Evaluation - Recycled Glass Processing System } \\
Operating Parameters
\end{tabular}

Table 5. Line Production Items for Recycled Glass Processing [20].

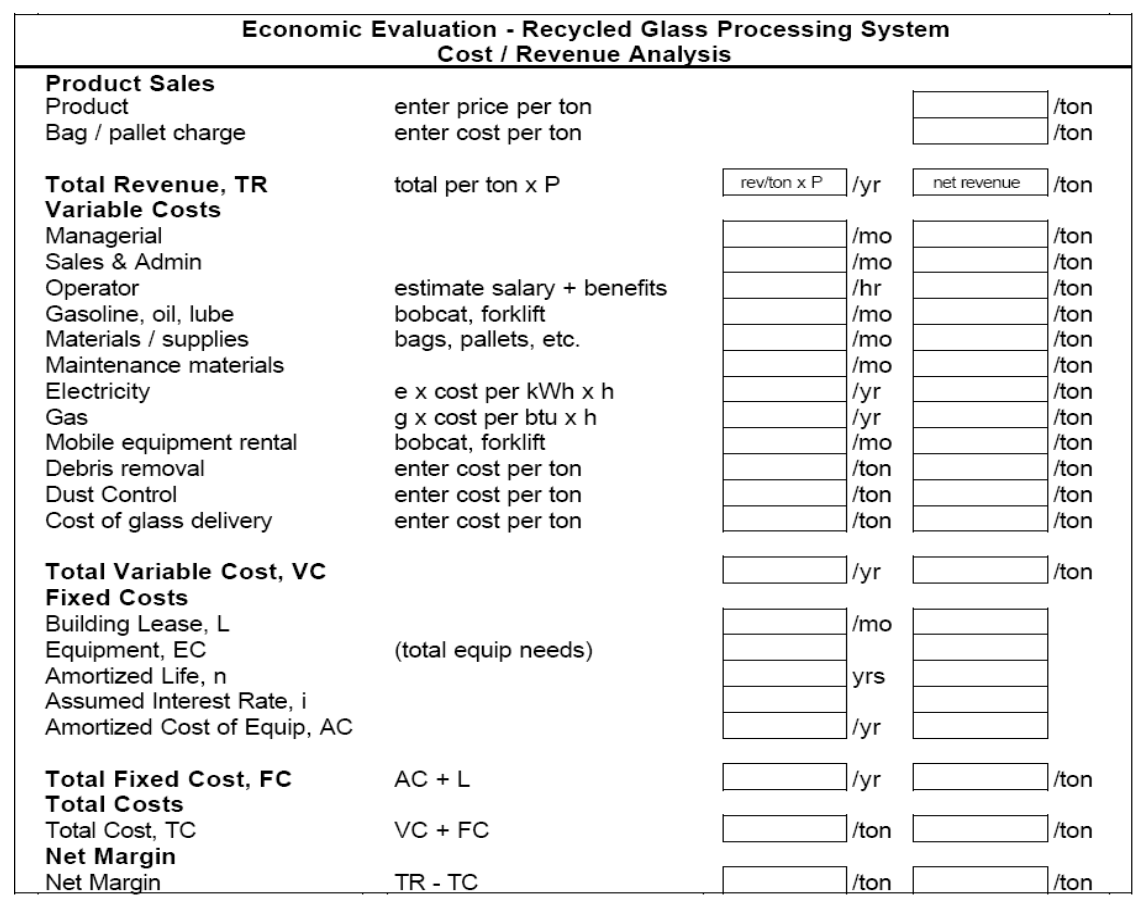




\subsection{Summary}

The different methods of cost estimation, such as standard cost estimation, activity based cost estimation, and marginal cost estimation were presented. The method of estimation used for the cost model is the standard cost estimation. The Canadian Industry Statistics indicated that the costs of materials and supplies saw a growth rate of 4.6 percent during the 1994-2003 period of glass manufacturing. The reduction in the costs of glass manufacturing is possible through the use of recycled cullet. The model developed by the Clear Washington Center used for estimation of recycled glass processing illustrates the major cost items in glass recycling. 


\section{CHAPTER 3}

\section{METHODOLOGY}

A spreadsheet model was developed using MS-Excel to perform the analysis and sensitivity study. The variables used were mix ratios of raw materials, unit costs of raw materials, direct labor costs, energy costs for melting, utilities costs, and store costs. The model is based on the flow process of glass manufacturing. The first step in the flow process is selecting the specific raw materials mix used to get the desired color for the product. The model calculates the material cost related to the specified mix of the ingredients. The raw materials are fed to the furnace for melting, and the cost for the furnace operation is calculated. The specific input needs for energy costs and manpower requirements for production testing and packing are listed.

\subsection{Model Input Data - Approach to Glass Industry}

The cost model opening screen is shown in Figure 9, and a click on the button "Start the Program" opens the program.

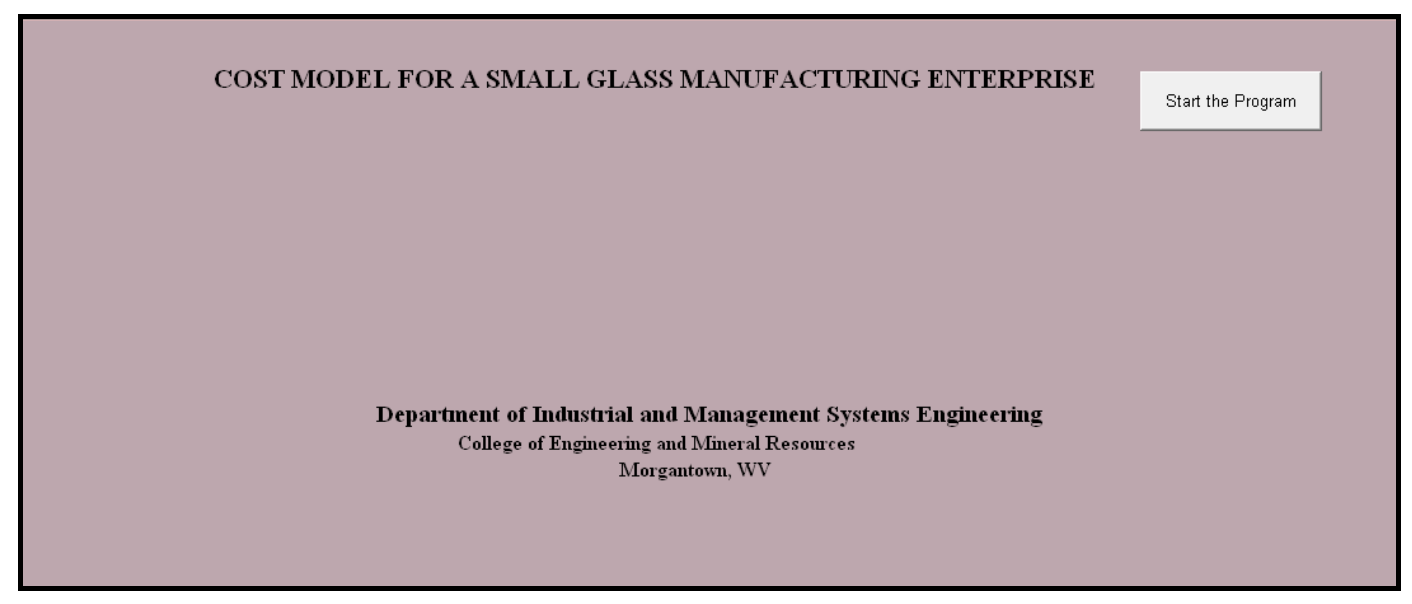

Figure 9. Screenshot of the Start of the Cost Model. 
The next screen shows another two buttons "Open data entry forms" and "Cost Estimating Form" as shown in Figure 10.

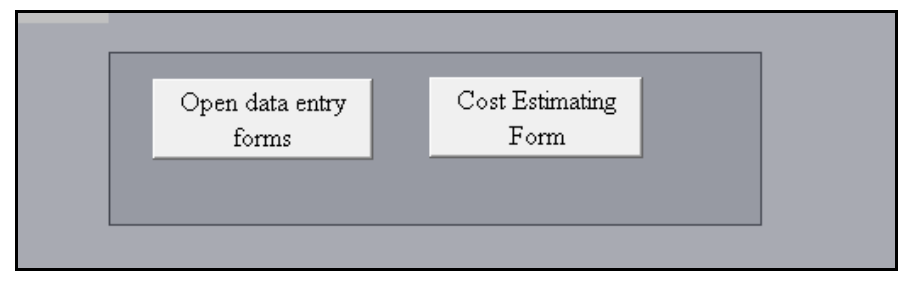

Figure 10. Screenshot of User Input Screen.

The screen "Open data entry forms" is basically for the input of user data. It has four buttons named "Material Input," "Other Inputs," "Display Results," and "Close Window," as shown in Figure 11.

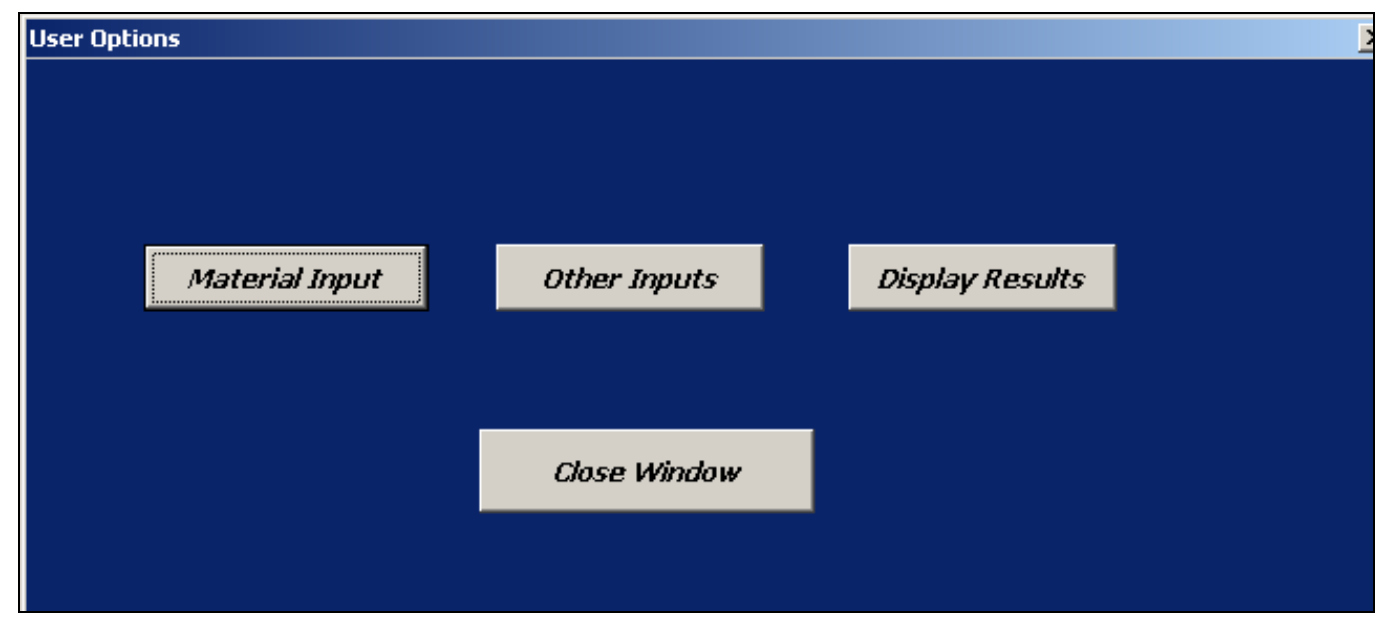

Figure 11. Screenshot of the Buttons for User Forms.

"Material Input" opens the user data form to enter the data for the material mix ratio and unit cost of the raw material, as shown in Figure 12. Figure 12 shows the list of different raw materials, mix ratio - the decimal amounts of raw material in the mix, and the unit cost - the \$/pound cost of the raw material. Waste costs and cullet return costs need to be entered. Other Inputs is a user form where the user enters the required input for the calculation of the costs and, 
this is fed into another MS Excel sheet, "Other Inputs." The user has the accessibility to review and edit the data entered into the form.

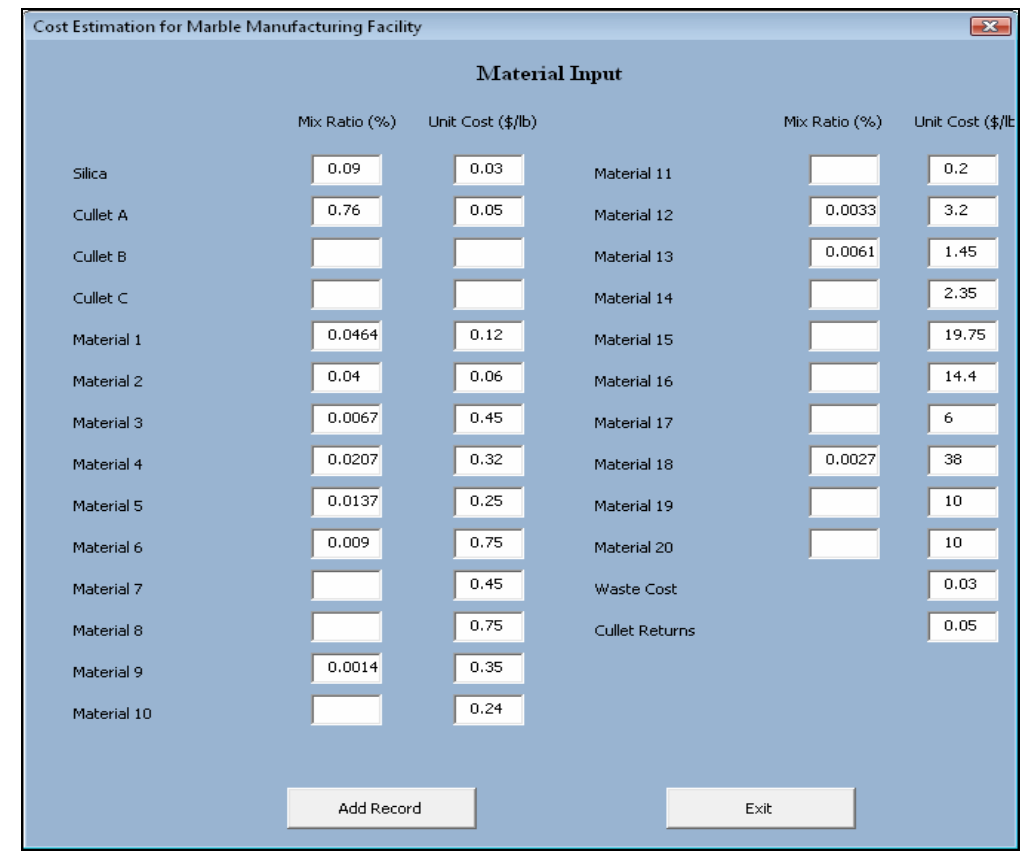

Figure 12. User Form for Material Input.

The "Other Inputs" form as shown in Figure 13 includes the production data, process yields, energy data, utilities information, manpower data, operating data, and overhead factors.

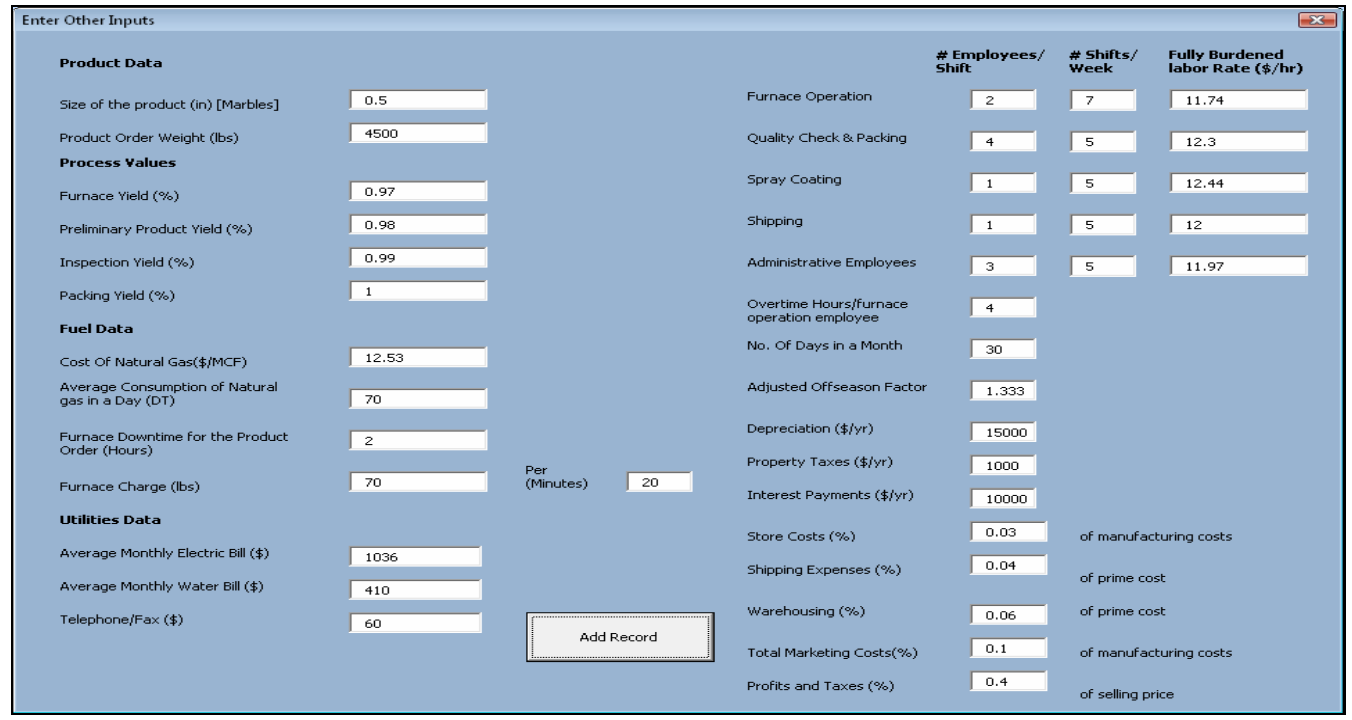

Figure 13. Other Inputs User Form. 
The product ordered weight is used to calculate the mix weight. The mix ratios and mix weight determine the amounts of the raw materials that are being fed to the furnace for the desired color of the product. There are four yields used in the model: furnace yield, preliminary product yield, inspection yield, and packing yield. The approximate yield percentages must be entered in the yield sheet to compute the mix weight. The furnace yield consists of equal amounts of, gases due to the chemical reactions in the process and the scrap from breakage (cullet).

The operation process yields must be entered as indicated in Figure 13 to estimate the required amount of raw material to produce the desired product order weight as shown in Table 6 and the amount of waste and cullet credits after the yields. Table 7 shows the material names, their unit costs, and the mix ratio used for the product.

Table 6. Material Yield Inputs.

\begin{tabular}{|l|c|c|c|c|}
\hline \multicolumn{2}{|c|}{ MATERIAL YIELD COSTS } & Lbs & $\begin{array}{c}\text { Waste } \\
\text { Cost(lbs) }\end{array}$ & $\begin{array}{c}\text { Cullet } \\
\text { Credit } \\
\text { (lbs) }\end{array}$ \\
\hline Furnace Yield & $97.00 \%$ & 4781.67 & 71.73 & 71.73 \\
\hline Preliminary Product Yield & $98.00 \%$ & 4638.22 & & 92.76 \\
\hline Inspection Yield & $99.00 \%$ & 4545.45 & & 45.45 \\
\hline Packing Yield & $100.00 \%$ & 4500.00 & & 0.00 \\
\hline Product & & 4500.00 & & \\
\hline
\end{tabular}

Other inputs include product description and parameters required for the calculation of the energy costs, labor costs, and the average utilities for a month. Table 8 shows the size and order weight data input for the product from Figure 13. Table 9 displays the energy cost inputs which are: the unit price of natural gas for 1000 cubic feet (MCF), the consumption of natural gas (Decatherm - DT) per day in the facility, the estimated down time per day, the weight of the raw material charge, and the amount of the time for melting the charge. A waste cost is the amount of material that leaves as gases, dust and slag. 
Table 7. Material Names, Mix Ratio and Unit cost

\begin{tabular}{|c|c|c|c|}
\hline S.No & Raw Material & $\begin{array}{l}\text { Mix } \\
\text { Ratio }\end{array}$ & $\begin{array}{c}\text { Unit } \\
\text { Cost }(\$ / \mathrm{lb})\end{array}$ \\
\hline 1 & Silica & 9.00 & $\$ 0.03$ \\
\hline 2 & Cullet A & 76.00 & $\$ 0.05$ \\
\hline 3 & Cullet B & & \\
\hline 4 & Cullet C & & \\
\hline 5 & Material 1 & 4.64 & $\$ 0.12$ \\
\hline 6 & Material 2 & 4.00 & $\$ 0.06$ \\
\hline 7 & Material 3 & 0.67 & $\$ 0.45$ \\
\hline 8 & Material 4 & 2.07 & $\$ 0.32$ \\
\hline 9 & Material 5 & 1.37 & $\$ 0.25$ \\
\hline 10 & Material 6 & 0.90 & $\$ 0.75$ \\
\hline 11 & Material 7 & & $\$ 0.45$ \\
\hline 12 & Material 8 & & $\$ 0.75$ \\
\hline 13 & Material 9 & 0.14 & $\$ 0.35$ \\
\hline 14 & Material 10 & & $\$ 0.24$ \\
\hline 15 & Material 11 & & $\$ 0.20$ \\
\hline 16 & Material 12 & 0.33 & $\$ 3.20$ \\
\hline 17 & Material 13 & 0.61 & $\$ 1.45$ \\
\hline 18 & Material 14 & & $\$ 2.35$ \\
\hline 19 & Material 15 & & $\$ 19.75$ \\
\hline 20 & Material 16 & & $\$ 14.40$ \\
\hline 21 & Material 17 & & $\$ 6.00$ \\
\hline 22 & Material 18 & 0.27 & $\$ 69.00$ \\
\hline 23 & Material 19 & & $\$ 10.00$ \\
\hline 24 & Material 20 & & $\$ 10.00$ \\
\hline 25 & Waste Cost & & $\$ 0.03$ \\
\hline 26 & Cullet Returns & & $\$ 0.05$ \\
\hline
\end{tabular}

Table 8. Product Input.

\begin{tabular}{|l|l|}
\hline PRODUCT DESCRIPTION & \\
\hline Size of the product & 0.5 inches \\
\hline Product Order Weight & $4500 \mathrm{lbs}$ \\
\hline Glass Density & $0.09393 \mathrm{pound} / \mathrm{in}^{3}$ \\
\hline
\end{tabular}

Table 9. Energy Cost Inputs.

\begin{tabular}{|c|c|c|c|c|}
\hline \multicolumn{2}{|c|}{ ENERGY COSTS INPUTS } & & & \\
\hline Cost of Natural Gas & $\$ 12.53$ & per MCF & & \\
\hline $\begin{array}{l}\text { Average consumption of natural gas } \\
\text { in a day }\end{array}$ & 70 & DT & & \\
\hline $\begin{array}{l}\text { Furnace downtime for the product } \\
\text { order }\end{array}$ & 2 & Hrs & & \\
\hline Furnace charge & 70 & lbs & 20 & minutes \\
\hline
\end{tabular}

Table 10 displays the input for the labor calculations. The inputs required are the number of employees in a shift, the fully burdened labor rate $(\$ /$ hour) of an employee in each manufacturing operation, and the area where personnel is involved. Labor is involved in furnace 
operation, quality checking, packing, and shipping. Administrative employees are for the management of the facility.

Table 10. Labor Inputs.

\begin{tabular}{|l|c|l|c|}
\hline DIRECT LABOR INPUTS & \#Employees/shift & $\begin{array}{c}\text { Fully } \\
\text { burdened } \\
\text { labor } \\
\text { rate } \mathbf{\$} / \mathbf{h o u r})\end{array}$ & $\begin{array}{l}\text { \# Shifts/ } \\
\text { Week }\end{array}$ \\
\hline Furnace Operation & 2 & $\$ 11.74$ & 14 \\
\hline Quality Check \& Packing & 4 & $\$ 12.30$ & 5 \\
\hline Spray Coating & 1 & $\$ 12.44$ & 5 \\
\hline Shipping & 1 & $\$ 12.00$ & 5 \\
\hline Administrative Employees & 3 & $\$ 11.97$ & 5 \\
\hline
\end{tabular}

Table 11 shows the input of average utilities for the facility in a month. Utilities include the electricity costs, water bills, and telephone/fax. This input is required to calculate the utilities cost for the product order.

\section{Table 11. Utilities Input.}

\begin{tabular}{|l|cc|}
\hline UTILITIES \\
\hline Average Monthly Electricity Bill & $\$$ & $1,036.00$ \\
\hline Average Monthly Water Bill & $\$$ & 410.00 \\
\hline Telephone/Fax & $\$$ & 60.00 \\
\hline
\end{tabular}

The number of days in a month is an input variable (Figure 13). For the calculation purposes, the number of days in a month is assumed to be 30 . The data for the facility modeled is only 9 months in a year. Hence the adjusted off season factor is input as $4 / 3$. The factor is multiplied with the direct labor cost to bridge the difference of operating months of the facility. The off season factor is 12 divided the number of months of operations per year. If the facility operates 12 months per year, the off season factor will be 1 . 
The formulae and the calculations used for the inputs entered:

If the diameter of the spherical product to be produced is known, the weight of each product could be estimated by calculating the volume of the product. Assuming the shape of the product to be a sphere, the volume is calculated by using the formula.

Volume of the product $=\left[(\pi / 6)^{*} d^{3}\right]$ cubic inches

Where $d$ is the diameter of the product in meters

The calculated volume is divided by the density of glass to determine the weight of each product. The density of glass is 0.0939310 pounds/cubic inches.

Weight of spherical product $=($ Volume of the product $*$ Density of glass $)(2)$

The unit weight of the product is used to approximate the number of products produced per pound. This formula is only for solid spheres, such as marbles.

The approximate weight of each raw material required to produce the desired weight of output is calculated by multiplying the percentage of mixes with required output. The required raw material weight over the yield percentages gives the weight needed for the production of final product.

$$
\begin{aligned}
& W_{i}=(X i) * W_{T} \\
& W_{T}=W_{o} /\left(Y_{1} * Y_{2} * Y_{3} * Y_{4}\right)
\end{aligned}
$$

Where

$X_{i}$ is the mix ratio percentages of each raw material ( $i$ varies 1 to $n$ ) after yield losses, $W_{T}$ is the required weight after yield to produce the desired output (lbs) after yield losses, Wo is the required output weight (lbs),

$W_{i}$ is the input weight (lbs) of material for the product, $Y_{1}, Y_{2}, Y_{3}, Y_{4}$ are the yield percentages for each manufacturing step. 
The unit cost of the raw material per pound and the mix ratio are used to find the individual material cost for the desired output weight. Material cost per desired output is the sum of all the individual material costs after yield percentages and waste cost difference cullet credit. The total material cost over the required product weight gives the product material cost per pound.

$$
\begin{gathered}
\text { Total Material Cost }=\sum_{i=1}^{n}(\mathrm{Wi} \text { *Ci) } \\
\text { Material cost / pound }(\$ / l b)=\left\{\sum_{i=1}^{n}(\mathrm{Wi} * \mathrm{Ci}) / \mathrm{W}_{T}\right\} \\
\text { Where } C_{i} \text { the unit cost of each raw material }(\$ / l b-i \text { varies } 1 \text { to } n)
\end{gathered}
$$

The furnace is typically charged every 20 minutes with the charge weight depending on the size of product to be produced. For example, products of sizes $1 / 2$ ", 5/8" have 70 pound charges, products of $3 / 4$ " diameter have 75 to 80 pound charges, products of 1 "

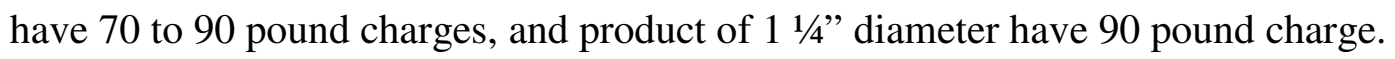

From the energy inputs, the average consumption of gas per day is known for every 20 minutes. The batch weight differs depending on the size of the product. For the sample model calculations, the consideration of the diameter of the product was $1 / 2$ " and the batch weight was $70 \mathrm{lbs}$. The furnace charge time was assumed to be 20 minutes or 3 charges per hour. The furnace charge weight and yields determine the number of batches required to produce the final product order weight.

\subsection{Model Calculations}

The material input data sheet (Figure 12) is the base for the material cost calculations. With the input of unit cost of raw materials, and percentage of mixes, the unit material cost per product is obtained by dividing the material cost per pound over the number of products. The 
number of products produced per pound can be calculated if the weight of each product is known.

Unit material cost of each product=(Material cost per pound/Number of products/pound) (7)

Number of products/pound $=[1 /($ Weight of each product $)($ lbs $)]$

Table 12 displays the model calculations for the material costs of the product that includes material weight before yield (lbs), and material cost before yield (\$), material weight after yield (lbs), which is dependent on the different yields in the manufacturing process. It also displays the unit material cost per pound and the number of products per pound.

The energy costs for the manufacturing show the energy consumption for the product order (DT), cost of natural gas for the product order $(\$)$, downtime cost of the product order, natural gas cost per pound of product order $(\$ / \mathrm{lb})$, and the number of batches required to produce the product order. Table 13 displays the energy costs. 
Table 12. Model Calculations for the Material Costs.

\begin{tabular}{|c|c|c|c|c|c|c|c|}
\hline \multicolumn{8}{|c|}{ MODEL } \\
\hline \multicolumn{2}{|c|}{ Size of the product(inches) - spherical } & \multirow{3}{*}{\begin{tabular}{|c|}
0.5 \\
0.00613 \\
\\
Mix \\
Ratio
\end{tabular}} & \multirow[b]{3}{*}{$\begin{array}{c}\text { Material } \\
\text { Weight } \\
\text { before yield } \\
\text { (lbs) }\end{array}$} & \multirow[b]{3}{*}{$\begin{array}{l}\text { Unit } \\
\text { Cost } \\
(\$ / l b)\end{array}$} & \multirow[b]{3}{*}{$\begin{array}{l}\text { Material } \\
\text { Cost } \\
\text { before } \\
\text { yield }(\$)\end{array}$} & \multirow[b]{3}{*}{$\begin{array}{c}\text { Material } \\
\text { Weight } \\
\text { after yield } \\
\text { (lbs) }\end{array}$} & \multirow[b]{3}{*}{$\begin{array}{c}\text { Material } \\
\text { Cost } \\
\text { after yield } \\
(\$)\end{array}$} \\
\hline \multicolumn{2}{|c|}{ Estimated wt. of each product (lbs) } & & & & & & \\
\hline S.No & Raw Material & & & & & & \\
\hline 1 & Silica & $9.00 \%$ & 405 & $\$ 0.03$ & $\$ 12.15$ & 430.35 & $\$ 12.91$ \\
\hline 2 & Cullet A & $76.00 \%$ & 3420 & $\$ 0.05$ & $\$ 171.00$ & 3634.07 & $\$ 181.70$ \\
\hline 3 & Cullet B & $0.00 \%$ & 0 & $\$ 0.00$ & $\$ 0.00$ & 0.00 & $\$ 0.00$ \\
\hline 4 & Cullet C & $0.00 \%$ & 0 & $\$ 0.00$ & $\$ 0.00$ & 0.00 & $\$ 0.00$ \\
\hline 5 & Material 1 & $4.64 \%$ & 209 & $\$ 0.12$ & $\$ 25.06$ & 221.87 & $\$ 26.62$ \\
\hline 6 & Material 2 & $4.27 \%$ & 192 & $\$ 0.06$ & $\$ 11.53$ & 204.18 & $\$ 12.25$ \\
\hline 7 & Material 3 & $0.67 \%$ & 30 & $\$ 0.45$ & $\$ 13.57$ & 32.04 & $\$ 14.42$ \\
\hline 8 & Material 4 & $2.07 \%$ & 93 & $\$ 0.32$ & $\$ 29.81$ & 98.98 & $\$ 31.67$ \\
\hline 9 & Material 5 & $1.37 \%$ & 62 & $\$ 0.25$ & $\$ 15.41$ & 65.51 & $\$ 16.38$ \\
\hline 10 & Material 6 & $0.90 \%$ & 41 & $\$ 0.75$ & $\$ 30.38$ & 43.04 & $\$ 32.28$ \\
\hline 11 & Material 7 & $0.00 \%$ & 0 & $\$ 0.45$ & $\$ 0.00$ & 0.00 & $\$ 0.00$ \\
\hline 12 & Material 8 & $0.00 \%$ & 0 & $\$ 0.75$ & $\$ 0.00$ & 0.00 & $\$ 0.00$ \\
\hline 13 & Material 9 & $0.14 \%$ & 6 & $\$ 0.35$ & $\$ 2.21$ & 6.69 & $\$ 2.34$ \\
\hline 14 & Material 10 & $0.00 \%$ & 0 & $\$ 0.24$ & $\$ 0.00$ & 0.00 & $\$ 0.00$ \\
\hline 15 & Material 11 & $0.00 \%$ & 0 & $\$ 0.20$ & $\$ 0.00$ & 0.00 & $\$ 0.00$ \\
\hline 16 & Material 12 & $0.33 \%$ & 15 & $\$ 3.20$ & $\$ 47.52$ & 15.78 & $\$ 50.49$ \\
\hline 17 & Material 13 & $0.61 \%$ & 27 & $\$ 1.45$ & $\$ 39.80$ & 29.17 & $\$ 42.29$ \\
\hline 18 & Material 14 & $0.00 \%$ & 0 & $\$ 2.35$ & $\$ 0.00$ & 0.00 & $\$ 0.00$ \\
\hline 19 & Material 15 & $0.00 \%$ & 0 & $\$ 19.75$ & $\$ 0.00$ & 0.00 & $\$ 0.00$ \\
\hline 20 & Material 16 & $0.00 \%$ & 0 & $\$ 14.40$ & $\$ 0.00$ & 0.00 & $\$ 0.00$ \\
\hline 21 & Material 17 & $0.00 \%$ & 0 & $\$ 6.00$ & $\$ 0.00$ & 0.00 & $\$ 0.00$ \\
\hline 22 & Material 18 & $0.00 \%$ & 0 & $\$ 38.00$ & $\$ 0.00$ & 0.00 & $\$ 0.00$ \\
\hline 23 & Material 19 & $0.00 \%$ & 0 & $\$ 10.00$ & $\$ 0.00$ & 0.00 & $\$ 0.00$ \\
\hline \multirow[t]{2}{*}{24} & Material 20 & $0.00 \%$ & 0 & $\$ 10.00$ & $\$ 0.00$ & 0.00 & $\$ 0.00$ \\
\hline & & $100.00 \%$ & 4500 & & $\$ 398.43$ & $4,781.67$ & $\$ 423.36$ \\
\hline 25 & Waste Cost & & 71.73 & $\$ 0.03$ & & & $\$ 2.15$ \\
\hline 26 & Cullet Returns & & 209.94 & $\$ 0.05$ & & & $(\$ 10.50)$ \\
\hline \multicolumn{2}{|c|}{ Net Material Cost } & & & & & & $\$ 415.02$ \\
\hline \multicolumn{2}{|c|}{ \# of marbles per pound } & & & & & & 163 \\
\hline \multicolumn{2}{|c|}{ Material Cost per unit weight $(\$ / l b)$} & & & & & & 0.0922 \\
\hline \multicolumn{2}{|c|}{$\begin{array}{l}\text { Unit material cost of product } \\
\text { (\$/product) }\end{array}$} & & & & & & 0.00057 \\
\hline
\end{tabular}


Table 13. Energy Costs of Manufacturing.

\begin{tabular}{|l|c|l|}
\hline \multicolumn{3}{|c|}{ Melting Costs ( 1 cubic feet = 1150 Btu) } \\
\hline & Amount & \multicolumn{1}{|c|}{ Units } \\
\hline Average consumption of natural gas in DT per day & $\mathbf{7 0}$ & DT \\
\hline Average consumption of natural gas in cubic feet per day & $\mathbf{6 0 . 8 7}$ & MCF \\
\hline Energy consumption for furnace per hour & $\mathbf{2 . 9 1 7}$ & DT/hour \\
\hline Cost of natural gas per one hour of the furnace & $\mathbf{\$ 3 6 . 5 5}$ & per hour \\
\hline Energy Consumption for the Product Order in DT & $\mathbf{6 2 . 5 0}$ & DT \\
\hline Energy Consumption for the Product Order in MCF & $\mathbf{5 4 . 3 5}$ & MCF \\
\hline Cost of natural gas & $\mathbf{\$ 1 2 . 5 3}$ & per DT \\
\hline Downtime Cost for the product order & $\mathbf{\$ 7 3 . 0 9}$ & \\
\hline Cost of natural gas for the product order & $\mathbf{\$ 8 5 6 . 2 2}$ & \\
\hline Natural gas cost per pound of product order $(\$ /$ lb) & $\mathbf{\$ 0 . 1 9 0}$ & \\
\hline Natural gas cost per product $(\$$ product) & $\mathbf{\$ 0 . 0 0 1 1 7}$ & \\
\hline \# of Batches required & $\mathbf{6 9}$ & \\
\hline
\end{tabular}

\section{ENERGY COST CALCULATIONS}

The average consumption of natural gas per day is taken from the input data sheet to determine the gas charge for each charge. For this model, the furnace charge was set at 20 minutes.

Consumption of natural gas per hour in DT = \{Average consumption per day $\}$

\section{4 hours}

The conversion of consumption of natural gas from decatherms to MCF ( 1000 cubic feet) is :

Average consumption of natural gas in cubic feet per day $=$ [(Average consumption of natural gas in DT per day * 10^6)/(1150 Btu)/1000] (10)

The objective is to find the consumption of gas for the product ordered weight. The consumption of the gas per hour is calculated. It is multiplied by the ratio of product order weight to the batch weight in an hour to find the gas usage for the total product order weight in decatherms (DT). 
Cost of natural gas per product order $=$ [Consumption of natural gas per hour in DT *(Product Order Weight/Raw Material Input Weight per hour)]

The cost of natural gas per product order weight is computed by multiplying the unit cost of gas per decatherms to the gas usage. The cost of natural gas per pound can be calculated by dividing the total gas cost over the product ordered weight. Cost of natural gas per product is determined by dividing the gas cost over the number of products. The number of furnace charges or batches required for the desired weight can be approximated by dividing the total product weight over the weight of one-time furnace charge (i.e., amount fed into the furnace every 20 minutes). MCF or 1000 cubic feet is a unit of measurement for natural gas, also same as 1000 cubic feet.

Number of batches required $=($ Raw material weight input after yield adjusted $/$ weight

$$
\text { per furnace charge) }
$$

\subsection{Output of the Cost Model}

It is the summary sheet that shows the costs of materials, labor and overheads associated with the production of the product.

$>$ The desired output weight of the products is known and hence the material cost after consideration of yields can be calculated.

All the results obtained in the model sheet are shown as summary in this sheet namely :

$>$ Unit cost of each product

$>$ Furnace cost per ordered weight

$>$ Furnace cost per pound

$>$ Furnace cost per product

$>$ Direct labor cost

$>$ Direct material cost

$>$ Total costs 
Table 14. Summary Costs Output Form.

\begin{tabular}{|l|c|c|}
\hline OUTPUT - Red Marble & $\mathbf{( \$ / l b )}$ & $\begin{array}{c}\text { Total Costs/Product } \\
\text { Order }\end{array}$ \\
\hline Unit Material Cost after yield & $\$ 0.0922$ & $\$ 415.02$ \\
\hline Unit Natural gas cost & $\$ 0.1903$ & $\$ 856.22$ \\
\hline Unit direct labor cost & $\$ 0.1508$ & $\$ 1,245$ \\
\hline Unit utilities cost & $\$ 0.0127$ & $\$ 47.63$ \\
\hline Unit selling expenses & $\$ 0.1535$ & $\$ 690.83$ \\
\hline Unit total cost & $\$ 0.7501$ & $\$ 3,897.15$ \\
\hline Profits \& Taxes & & $\$ 1,670.21$ \\
\hline Unit selling price & $\$ 1.237$ & \\
\hline
\end{tabular}

\subsection{Detailed Estimation}

The economic analysis method used in this evaluation was developed by the American Association of Cost Engineers (AACE). This sheet gives information about the split of costs for manufacturing the end product. It consists of:

1. Manufacturing/Factory cost,

2. Production costs,

3. Total costs, and

4. Selling price and profit.

- Manufacturing/Factory costs comprise total prime costs and total indirect costs. Total prime costs is the sum of direct labor, direct materials, and direct engineering expenses. Direct labor in this model considers the personnel involved with the mix of raw materials, furnace charging, quality inspection to determine if the manufactured products are within the tolerance limits, packing, and shipping to the customer. The furnace operation employees work 24 hours a day, 7 days a week in a 12 hour shift ( i.e. 168 hours per week) whereas all other workers work 8 hours a day, 5 days a week ( i.e. 40 hours per week). The labor cost per pound and labor cost per product order is multiplied 
by the adjusted off-season factor to set the differences in costs when the industry is not in operating conditions. It also includes the furnace costs for melting the cullet. A total indirect cost includes indirect materials and also adds the sum of utilities cost to it, which includes water and electricity. It is calculated as dollars per product order. Depreciation per year $(\$ / y r)$, property taxes per year and interest payments per year are entered as inputs.

No. of hours for completion of product order (furnace operation) $=($ Product order quantity/furnace charge for 1 hour)

No. of hours for completion of product order (quality check, spray coating, shipping and administrative employees $)=[($ Product order quantity/furnace charge for 1 hour $)]$ (Total hours of furnace operation per week - 168 hrs / Total hours of (quality check, spray coating, shipping and administrative employees) per week - $40 \mathrm{hrs})]$

Direct labor cost/product order $=($ No. of employees/shift $*$ fully burdened labor rate $*$ No. of hours for completion of product order)

Direct Labor cost per month $=($ No. of employees $/$ shift $*$ fully burdened labor rate $*$ No. of hours in a shift * No. of days in a month)

Direct labor cost/pound $=($ Labor cost per month/No. of days in a month/24 hours in a day)/[(Charge per 20 minutes * No. of charges in an hour)*(Adjusted off- season factor)]

- Production plant cost constitutes administrative salaries, and is the sum of production plant cost and total manufacturing cost. Administrative salaries are calculated as the product of number of employees per shift, the number of hours per shift, fully burdened labor rate (\$/hour) and adjusted off-season factor. 
- Total costs are the sum of manufacturing/factory cost, production plant cost, and comprises selling expenses. Selling expenses include marketing costs, shipping expenses, and warehousing or inventory costs. Marketing and store costs are taken as a percentage of total manufacturing costs, whereas shipping expenses and inventory costs are calculated as a percentage of prime costs. The percentage of manufacturing costs for marketing and store costs is a variable.

- Finally, mark-up is a percentage of selling price. Some of the factors that can be considered for mark-up were taxes and profits. The difference between the cost price of an item and its selling price is termed as mark-up. Unit selling price can be determined from the batch size by dividing the selling price with total number of end products.

Selling price $=[$ Total cost for the product $/(1-$ mark-up $(\%))]$

Unit selling price $=($ Selling price/Product order weight $)(\$ / l b)$

From Table 15 , the $\%$ of total costs and the unit total cost $(\$ / \mathrm{lb})$ can be known. The direct labor cost is $31.94 \%$ of the total cost, direct material cost is $10.65 \%$ of the total cost, energy cost is $21.97 \%$ of the total cost, depreciation, property taxes and interest payments is $11.13 \%$ of the total cost, utilities cost is $1.75 \%$ of the total cost, administrative costs is $4.44 \%$ of the total cost, and the selling expenses are $17.73 \%$ of the total cost. Figure 14 shows the split of the percent of costs to the total costs.

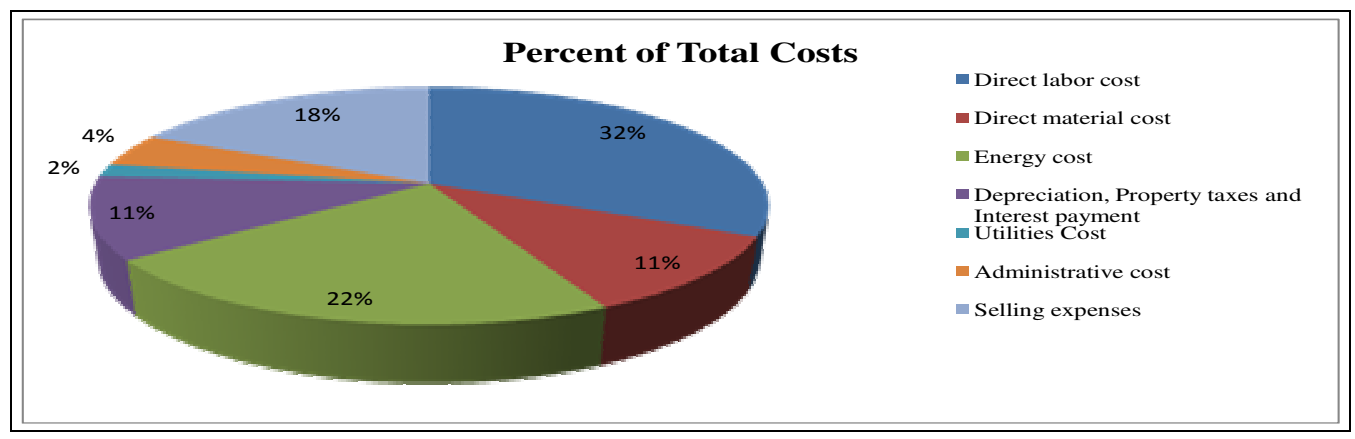

Figure 14. Percent of Total Costs. 
Table 15. Detailed Estimation.

\begin{tabular}{|c|c|c|c|c|c|c|c|c|c|}
\hline \multicolumn{9}{|c|}{ Detailed form for Red Marble } & \multirow{2}{*}{$\begin{array}{c}\text { Percent } \\
\text { of Total } \\
\text { Costs }\end{array}$} \\
\hline \multicolumn{2}{|c|}{ Manufacturing/Factory Cost } & & & & & & & & \\
\hline \multicolumn{2}{|c|}{ Prime Costs } & & & & & & & & \\
\hline Direct labor & Hours & Rates & Shifts & Cost/Product & $\$ / l b$ & Total Cost & \$/month & & \\
\hline Furnace Operation & 22.77 & $\$ 11.74$ & 1.90 & $\$ 713$ & $\$ 0.151$ & & $\$ 17.107$ & & \\
\hline OualitvCheck\& & 5.42 & $\$ 12.30$ & 0.45 & $\$ 356$ & $\$ 0.035$ & & $\$ 11.108$ & & \\
\hline Sprav Coating & 5.42 & $\$ 12.44$ & 0.45 & $\$ 90$ & $\$ 0.025$ & & $\$ 2.986$ & & \\
\hline Shipping & 5.42 & $\$ 12.00$ & 0.45 & $\$ 87$ & $\$ 0.024$ & & $\$ 2.880$ & & \\
\hline Direct Supervision & & $0 \%$ & \multicolumn{2}{|c|}{ of direct labor } & & $\$ 0.00$ & & & \\
\hline Direct Labor Cost & & & & & & $\$ 1.245$ & $\$ 46,362$ & & $31.94 \%$ \\
\hline Direct Materials & wt/unit) & Rates & & Cost/Product & & & & & \\
\hline Silica & 430.35 & $\$ 0.03$ & & $\$ 12.91$ & & & & & \\
\hline Cullet A & 3634.07 & $\$ 0.05$ & & $\$ 181.70$ & & & & & \\
\hline Cullet B & 0.00 & $\$ 0.00$ & & $\$ 0.00$ & & & & & \\
\hline Cullet C & 0.00 & $\$ 0.00$ & & $\$ 0.00$ & & & & & \\
\hline Material 1 & 221.87 & $\$ 0.12$ & & $\$ 26.62$ & & & & & \\
\hline Material 2 & 204.18 & $\$ 0.06$ & & $\$ 12.25$ & & & & & \\
\hline Material 3 & 32.04 & $\$ 0.45$ & & $\$ 14.42$ & & & & & \\
\hline Material 4 & 98.98 & $\$ 0.32$ & & $\$ 31.67$ & & & & & \\
\hline Material 5 & 65.51 & $\$ 0.25$ & & $\$ 16.38$ & & & & & \\
\hline Material 6 & 43.04 & $\$ 0.75$ & & $\$ 32.28$ & & & & & \\
\hline Material 7 & 0.00 & $\$ 0.45$ & & $\$ 0.00$ & & & & & \\
\hline Material 8 & 0.00 & $\$ 0.75$ & & $\$ 0.00$ & & & & & \\
\hline Material 9 & 6.69 & $\$ 0.35$ & & $\$ 2.34$ & & & & & \\
\hline Material 10 & 0.00 & $\$ 0.24$ & & $\$ 0.00$ & & & & & \\
\hline Material 11 & 0.00 & $\$ 0.20$ & & $\$ 0.00$ & & & & & \\
\hline Material 12 & 15.78 & $\$ 3.20$ & & $\$ 50.49$ & & & & & \\
\hline Material 13 & $\begin{array}{l}13.10 \\
29.17\end{array}$ & $\$ 1.45$ & & $\$ 42.29$ & & & & & \\
\hline Material 14 & 0.00 & $\$ 2.35$ & & $\$ 0.00$ & & & & & \\
\hline Material 15 & 0.00 & $\$ 19.75$ & & $\$ 0.00$ & & & & & \\
\hline Material 16 & 0.00 & $\$ 14.40$ & & $\$ 0.00$ & & & & & \\
\hline Material 17 & 0.00 & $\$ 14.40$ & & $\$ 0.00$ & & & & & \\
\hline Material 18 & $\frac{0.00}{0.00}$ & $\$ 38.00$ & & $\$ 0.00$ & & & & & \\
\hline Material 19 & 0.00 & $\$ 10.00$ & & $\$ 0.00$ & & & & & \\
\hline Material 20 & 0.00 & $\$ 10.00$ & & $\$ 0.00$ & & & & & \\
\hline Waste Cost & 71.73 & $\$ 0.03$ & & $\$ 2.15$ & & & & & \\
\hline Cullet Returns & 209.94 & $\$ 0.05$ & & $(\$ 10.50)$ & $\$ / \mathrm{lb}$ & & & & \\
\hline Direct Material Cost & & & & & $\$ 0.092$ & $\$ 415.02$ & & & $(10.65) \%$ \\
\hline & \$/DT & DT/Orde & & Cost/Product & $\$ / 1 b$ & & & & \\
\hline Melting Costs & $\$ 12.53$ & 68.33 & & $\$ 856.22$ & $\$ 0.19$ & $\$ 856.22$ & & & $(2197) \%$ \\
\hline \multicolumn{3}{|c|}{ Total Material and Furnace Costs /Pt Odr } & & & & $\$ 1,271$ & & & $32.62 \%$ \\
\hline Manufacturing & Amountt & Rate & Batch & Total Cost & & & & & \\
\hline \multirow[t]{2}{*}{ Tooling } & 1 Set & $\$ 3.000$ & 600 & $\$ 15.00$ & & $\$ 15.00$ & & & \\
\hline & & $\$ /$ vear & & \$/Pound & & & \$/month & & \\
\hline Depreciation & & $\$ 15.000$ & & $\$ 0.074$ & & $\$ 188.32$ & $\$ 1.250$ & & $11.13 \%$ \\
\hline Property Taxes & & $\$ 10,000$ & & $\$ 0.050$ & & $\$ 223.21$ & $\$ 833$ & & \\
\hline Interest Pavment & & $\$ 1.000$ & & $\$ 0.005$ & & $\$ 22.32$ & $\$ 83$ & & \\
\hline Total Prime Cost & & & & & & & & $\$ 2.965$ & $76.08 \%$ \\
\hline Indirect Materials & & $5 \%$ & of dire & erials & & $\$ 20.75$ & & & \\
\hline \multirow[t]{2}{*}{ Utilities } & & & & & & & & & \\
\hline & \$ /Month & \$/Batch & & & $\$ / \mathrm{lb}$ & & & & \\
\hline Electricity & $\$ 1.036 .0$ & $\$ 0.480$ & & & $\$ 0.01$ & & & & \\
\hline Water & $\$ 410$ & $\$ 0.190$ & & & $\$ 0.002$ & & & & \\
\hline Telephone/Fax & $\$ 60.0$ & $\$ 0.028$ & & & $\$ 0.000$ & & & & \\
\hline & $\$ 1.446 .0$ & $\$ 0.697$ & & & $\$ 0.013$ & $\$ 47.63$ & & & \\
\hline Total Indirect Costs & & & & & & & & & $1.75 \%$ \\
\hline Mfg Cost & & & & & & & & $\$ 3.033$ & $77.83 \%$ \\
\hline Plant Administrative & & Rate & \# shifts & $\$ /$ Order & $\$ / 1 b$ & & \$/month & & \\
\hline Administrative & & $\$ 11.97$ & 0.45 & $\$ 173.01$ & $\$ 0.07$ & & $\$ 11.488 .3$ & & \\
\hline Administrative $\mathrm{t}$ & & & & & & $\$ 173.01$ & & & $4.44 \%$ \\
\hline Production Costs & & & & & & & & $\$ 3.206$ & $82.27 \%$ \\
\hline Selling Expenses & & & & & $\$ / \mathrm{lb}$ & & & & \\
\hline Store Costs & & $3 \%$ & of man & ring costs & $\$ 0.021$ & $\$ 91.00$ & & & \\
\hline Shipping Expenses & & $4 \%$ & of prim & & $\$ 0.028$ & $\$ 118.6$ & & & \\
\hline Warehousing & & $6 \%$ & of prim & & $\$ 0.041$ & $\$ 177.9$ & & & \\
\hline Total Marketing & & $10 \%$ & of man & ring costs & $\$ 0.070$ & $\$ 303.33$ & & & \\
\hline & & & & & & $\$ 690.8$ & & & $17.7 \%$ \\
\hline Total Costs & & & & & & & & $\$ 3.897$ & $100.00 \%$ \\
\hline Mark - up & & & & & & & & & \\
\hline Profit and Taxes & & $30 \%$ & of Selli & & & $\$ 1.670 .21$ & & & \\
\hline Selling Price & & & & & & $\$ 5.567$ & & $\$ 5.567$ & \\
\hline Unit Selling Price- $\$ / 1 b$ & & & & & $\$ 1.24$ & & & & \\
\hline
\end{tabular}




\section{CHAPTER 4}

\section{RESULTS AND DISCUSSION}

A sensitivity analysis was done by varying parameters, and the corresponding results were recorded. The results were calculated using the variables and the equations discussed previously. The variables that were changed were the furnace cost per 1000 cubic feet (MCF), cost of cullet per pound, change in shut-down period of the facility, and change in the customerordered product weight.

\subsection{Cost of Natural Gas Price per MCF}

The price of natural gas was altered by an increase from $50 \%$ to $200 \%$ to determine the effect on unit cost of the product produced. These costs are calculated based on the assumption of fixed product order weight, the mix ratio of the raw materials kept constant, and the diameter of the product assumed at $1 / 2 "$. The base price of the natural gas considered was $\$ 12.53$ per MCF. The facility operates only 9 months in a year. The operational hours were 2 shifts per day, seven

days a week. The unit costs for each variation are listed in Table 16. Table 16 shows that the unit cost per pound of the product is directly proportional to the increase in the fuel cost. Each $\$ 1 / \mathrm{MCF}$ increase in gas cost led to a $\$ 0.02 /$ pound increase in total product cost. 
Table 16. Total Unit Cost /Pound of Natural Gas for Product Order.

\begin{tabular}{|c|c|c|c|}
\hline $\begin{array}{c}\text { Cost of Natural } \\
\text { gas }(\$ / \mathrm{MCF})\end{array}$ & $\begin{array}{c}\text { Unit price of } \\
\text { natural gas }(\$ / \mathrm{lb})\end{array}$ & $\begin{array}{c}\text { Total cost of gas for } \\
\text { product order } \$ \text { ) }\end{array}$ & $\begin{array}{c}\text { Total Product } \\
\text { Cost/Product } \\
\text { Order } \$ \text { ) }\end{array}$ \\
\hline$\$ 5.00$ & $\$ 0.08$ & $\$ 341.67$ & $\$ 2,763$ \\
\hline$\$ 6.00$ & $\$ 0.09$ & $\$ 410.00$ & $\$ 2,853$ \\
\hline$\$ 7.00$ & $\$ 0.11$ & $\$ 478.33$ & $\$ 2,944$ \\
\hline$\$ 8.00$ & $\$ 0.12$ & $\$ 546.67$ & $\$ 3,034$ \\
\hline$\$ 9.00$ & $\$ 0.14$ & $\$ 615.00$ & $\$ 3,124$ \\
\hline$\$ 10.00$ & $\$ 0.15$ & $\$ 683.30$ & $\$ 3,214$ \\
\hline$\$ 11.00$ & $\$ 0.17$ & $\$ 751.63$ & $\$ 3,304$ \\
\hline$\$ 12.00$ & $\$ 0.18$ & $\$ 819.96$ & $\$ 3,394$ \\
\hline$\$ 13.00$ & $\$ 0.20$ & $\$ 888.29$ & $\$ 3,484$ \\
\hline$\$ 14.00$ & $\$ 0.21$ & $\$ 956.62$ & $\$ 3,574$ \\
\hline$\$ 15.00$ & $\$ 0.23$ & $\$ 1,024.95$ & $\$ 3,664$ \\
\hline$\$ 16.00$ & $\$ 0.24$ & $\$ 1,093.28$ & $\$ 3,754$ \\
\hline$\$ 17.00$ & $\$ 0.26$ & $\$ 1,161.61$ & $\$ 3,844$ \\
\hline$\$ 18.00$ & $\$ 0.27$ & $\$ 1,229.94$ & $\$ 3,934$ \\
\hline$\$ 19.00$ & $\$ 0.29$ & $\$ 1,298.27$ & $\$ 4,024$ \\
\hline$\$ 20.00$ & $\$ 0.30$ & $\$ 1,366.60$ & $\$ 4,114$ \\
\hline$\$ 21.00$ & $\$ 0.32$ & $\$ 1,434.93$ & $\$ 4,204$ \\
\hline$\$ 22.00$ & $\$ 0.33$ & $\$ 1,503.26$ & $\$ 4,294$ \\
\hline$\$ 23.00$ & $\$ 0.35$ & $\$ 1,571.59$ & $\$ 4,384$ \\
\hline$\$ 24.00$ & $\$ 0.36$ & $\$ 1,639.92$ & $\$ 4,474$ \\
\hline$\$ 25.00$ & $\$ 0.38$ & $\$ 1,708.25$ & $\$ 4,564$ \\
\hline$\$ 26.00$ & $\$ 0.39$ & $\$ 1,776.58$ & $\$ 4,654$ \\
\hline$\$ 27.00$ & $\$ 0.41$ & $\$ 1,844.91$ & $\$ 4,744$ \\
\hline$\$ 28.00$ & $\$ 0.42$ & $\$ 1,913.24$ & $\$ 4,834$ \\
\hline$\$ 29.00$ & $\$ 0.44$ & $\$ 1,981.57$ & $\$ 4,924$ \\
\hline$\$ 30.00$ & $\$ 0.45$ & $\$ 2,049.90$ & $\$ 5,014$ \\
\hline & & & \\
\hline
\end{tabular}

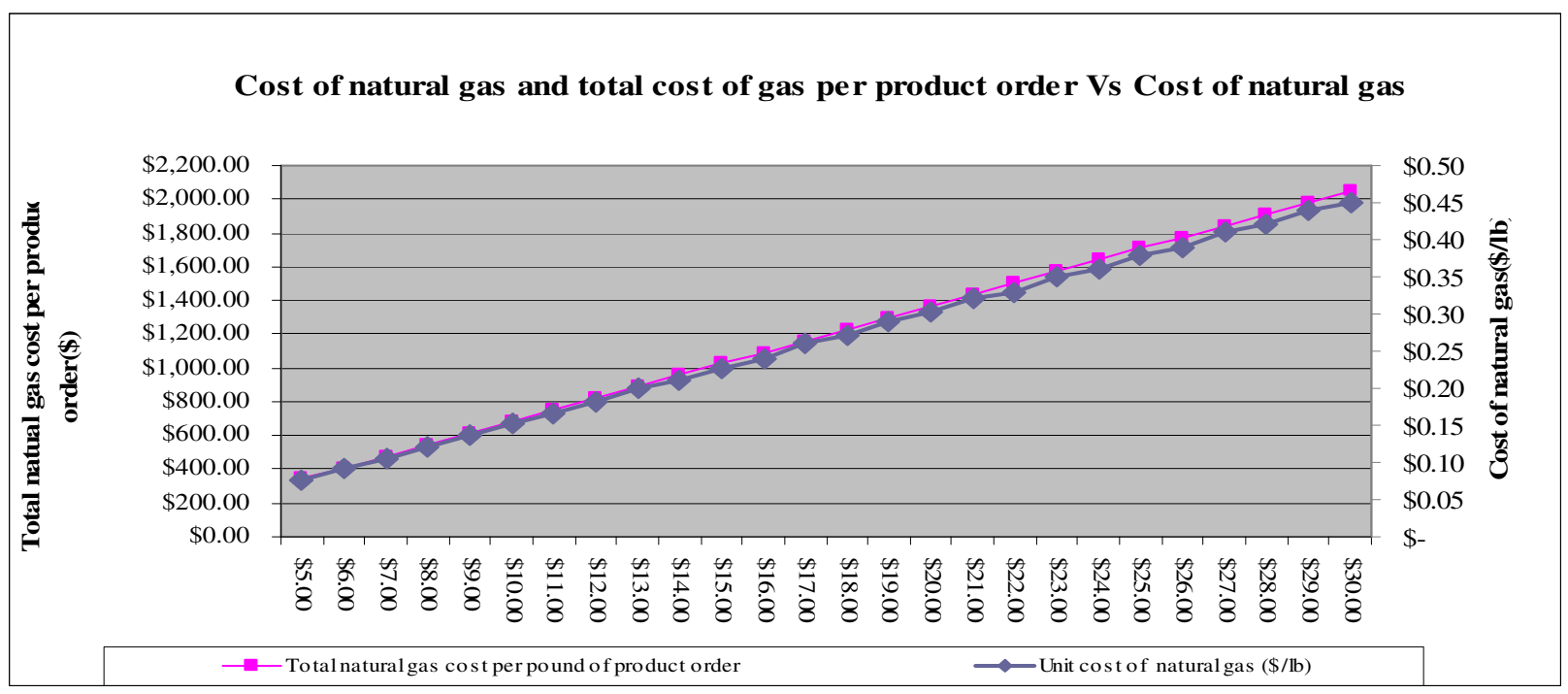

Figure 15. Unit Cost of Natural Gas and Total Gas Cost for the Product Order Vs Unit Cost of Natural Gas. 


\subsection{Unit Cullet Cost per Pound of Product Order}

The cullet cost was varied with respect to the base price of $\$ 0.05 / \mathrm{lb}$ up to $\$ 0.5 / \mathrm{lb}$. These costs are calculated based on the assumptions discussed in Section 4.1. For every $\$ 0.10$ increase in cost of cullet, the total material cost per pound of product order is increased by $\$ .08$. Total product cost increased by $\$ 0.45 / \mathrm{lb}$ for an increase in cullet cost of $\$ 0.40 / \mathrm{lb}$.

Table 17. Total Unit Material Cost of the Product Order.

\begin{tabular}{|c|c|c|}
\hline $\begin{array}{c}\text { Unit Cullet } \\
\text { Cost }(\$ / \mathrm{lb})\end{array}$ & $\begin{array}{c}\text { Unit Material Cost } \\
\text { of Product Order } \\
(\$ / \mathrm{lb})\end{array}$ & $\begin{array}{c}\text { Total Product } \\
\text { Cost }(\$)\end{array}$ \\
\hline 0.05 & $\$ 0.0932$ & $\$ 3,443$ \\
\hline 0.15 & $\$ 0.1600$ & $\$ 3,944$ \\
\hline 0.25 & $\$ 0.2449$ & $\$ 4,445$ \\
\hline 0.35 & $\$ 0.3208$ & $\$ 4,945$ \\
\hline 0.45 & $\$ 0.3966$ & $\$ 5,446$ \\
\hline
\end{tabular}

Figure 16 shows that there is a linear relation between increase in cost of cullet and total unit cost.

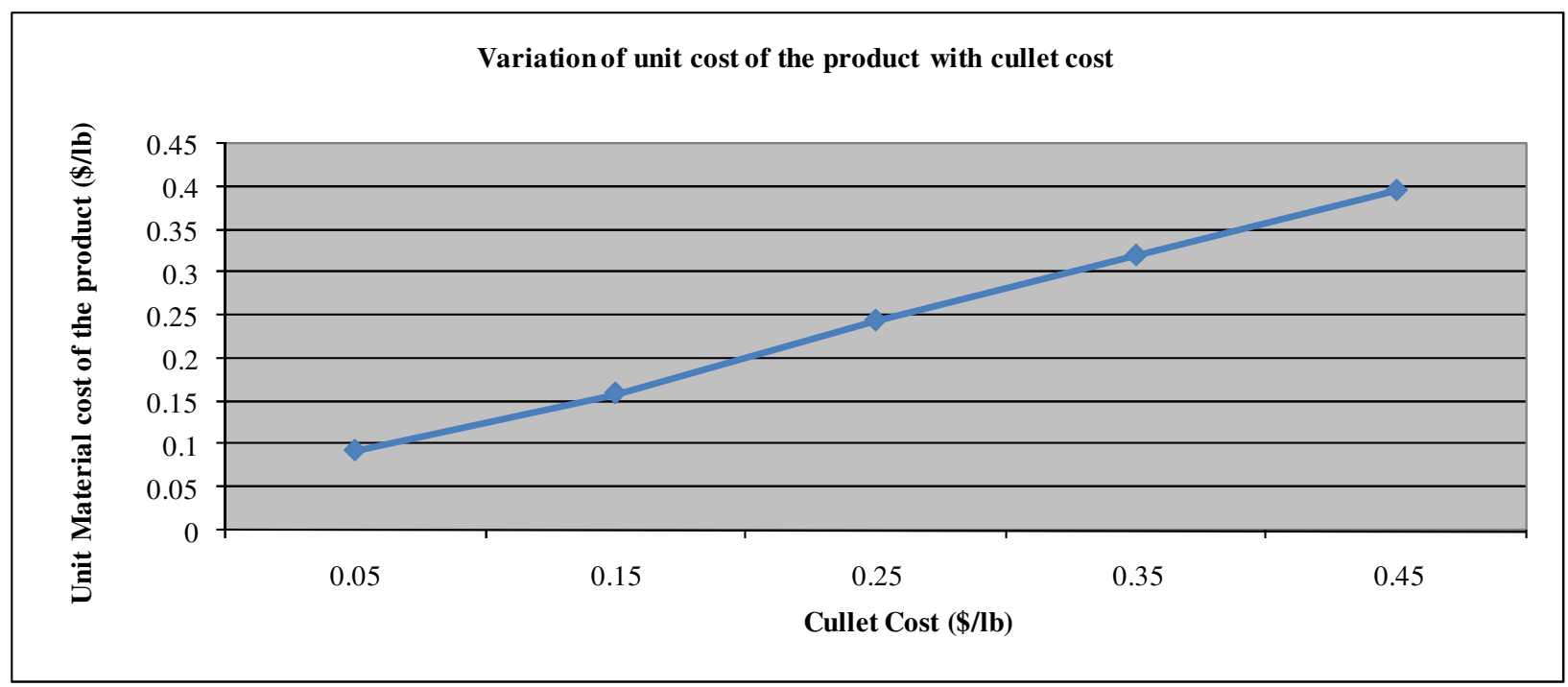

Figure 16. Variation in Total Unit Cost per Product Order with Change in Cullet Cost. 


\subsection{Variation in Shutdown Time of the Facility}

The shutdown time period (adjusted off-season factor) of the facility is an important factor to be considered, because it affects the cost of the product. The reason it affects the cost is that personnel are paid during the shutdown period for maintenance purpose, and the costs should be recovered through the product. The shutdown time period was varied between 5 weeks per year to 13 weeks per year. The variation of the cost associated with the change in shutdown is studied. It can be observed from the results in Table 18 that there is an increase of $\$ 0.01 / \mathrm{lb}$ for every increase in shutdown period of every two weeks.

Table 18. Total Unit Cost of Product with Change in Shutdown Period.

\begin{tabular}{|c|c|c|}
\hline $\begin{array}{c}\text { Adjusted off- } \\
\text { season factor }\end{array}$ & $\begin{array}{c}\text { Shutdown } \\
\text { Months/year }\end{array}$ & $\begin{array}{c}\text { Unit Cost of Product } \\
\text { Order }(\$ / \mathrm{lb})\end{array}$ \\
\hline 1.3333 & 13 Weeks & $\$ 0.8660$ \\
\hline 1.2632 & 11 Weeks & $\$ 0.8449$ \\
\hline 1.2000 & 9 Weeks & $\$ 0.8258$ \\
\hline 1.1429 & 7 Weeks & $\$ 0.8084$ \\
\hline 1.0909 & 5 Weeks & $\$ 0.7927$ \\
\hline 1 & 0 Weeks & $\$ 0.7651$ \\
\hline
\end{tabular}

\subsection{Variation in Unit Price of Selenium}

The price of raw materials is also a significant factor to be considered, because it affects the overall cost of the product. The inclusion of the raw material selenium varies the material cost of the product, though the mix percentage is less. The assumption of mix ratio of the material is $0.27 \%$. For every $10 \%$ increase in the base price $(\$ 38)$ of selenium, the total cost of the product order increased by $2 \%$. The variation of the cost associated with the change in unit price of the raw material is studied. For a $\$ 1 / \mathrm{lb}$ increase in cost of selenium, the total product cost increased by $\$ 0.004 / 1 b$. 
Table 19. Total Cost of Product Order with Variation in Unit Price of Selenium.

\begin{tabular}{|c|c|c|c|}
\hline $\begin{array}{c}\text { Unit price of } \\
\text { Selenium }(\$ / \mathrm{lb})\end{array}$ & $\begin{array}{c}\text { Unit material cost for } \\
\text { product order }(\$ / \mathrm{lb})\end{array}$ & $\begin{array}{c}\text { Total Cost/ } \\
\text { Product Order }\end{array}$ & $\begin{array}{c}\% \text { of Total } \\
\text { Product Cost }\end{array}$ \\
\hline$\$ 39.00$ & $\$ 0.2026$ & $\$ 4,420$ & $21 \%$ \\
\hline$\$ 42.00$ & $\$ 0.2142$ & $\$ 4,488$ & $21 \%$ \\
\hline$\$ 45.00$ & $\$ 0.2258$ & $\$ 4,564$ & $22 \%$ \\
\hline$\$ 48.00$ & $\$ 0.2345$ & $\$ 4,618$ & $23 \%$ \\
\hline$\$ 51.00$ & $\$ 0.2403$ & $\$ 4,654$ & $23 \%$ \\
\hline$\$ 54.00$ & $\$ 0.2490$ & $\$ 4,708$ & $24 \%$ \\
\hline$\$ 57.00$ & $\$ 0.2577$ & $\$ 4,762$ & $24 \%$ \\
\hline$\$ 60.00$ & $\$ 0.2664$ & $\$ 4,815$ & $25 \%$ \\
\hline$\$ 63.00$ & $\$ 0.2751$ & $\$ 4,869$ & $25 \%$ \\
\hline$\$ 66.00$ & $\$ 0.2838$ & $\$ 4,923$ & $26 \%$ \\
\hline$\$ 69.00$ & $\$ 0.2925$ & $\$ 4,977$ & $26 \%$ \\
\hline
\end{tabular}




\section{CHAPTER 5}

\section{CONCLUSIONS}

The cost model shows the costs for a small glass manufacturing enterprise. The model provides the material costs, energy costs, depreciation costs, and overhead expenses such as warehouse costs, indirect materials cost, labor costs, and selling expenses for a specified order quantity. These costs aid the management in decision making about the cost of manufacturing the product. The model estimates the selling price of the product. The model was studied for variations in prices of natural gas and raw materials. For an increase of natural gas cost from $\$ 5 / \mathrm{MCF}$ to $\$ 10 / \mathrm{MCF}$, the change in unit price of natural gas increased from $\$ .07 / \mathrm{lb}$ to $\$ .15 / \mathrm{lb}$. For every $\$ 1 / \mathrm{MCF}$ increase in cost of natural gas, the product cost increased by $\$ 0.02 /$ pound. For an increase of $\$ .10 / \mathrm{lb}$ in unit cullet cost, the unit material cost of the product increased by $\$ .08 / \mathrm{lb}$.

\section{FUTURE WORK}

1. The sensitivity analysis performed on the model was not automated. The model should include a software tool which can perform the sensitivity analysis by taking different scenarios of inputs. For example, the user should give the variable factor and the amount of variation and the tool should display the result of the variation on the total product cost.

2. The model doesn't include the cost analysis of setting up the manufacturing plant. For example, the building cost and land costs are not taken in to consideration though the depreciation data is used.

3. The model doesn't include the conversion between manufacturing operation shifts and other regular worker shifts if both are working equivalent hours. The model assumes that the furnace 
operation workers work 24 hours a day, 7 days a week (168 hours per week) and other regular workers work 8 hours a day, 5 days a week (40 hours per week). For example, if the regular workers work 7 days a week as furnace operation workers, the model doesn't take any input for the calculation. 


\section{BIBLIOGRAPHY}

[1] What is Glass? http://www.wisegeek.com/what-is-glass.htm (Last Accessed 11/04/2007)

[2] Holladay, Andrea Rae (2005). Modeling and Control of a Small Glass Furnace.

Master's Thesis, West Virginia University (On-line Abstract).

Available: https://eidr.wvu.edu/files/4324/Holladay_Andrea_thesis.pdf

[3] Shelby, James E. Introduction to Glass Science and Technology. Royal Society of chemistry, Cambridge, UK, 1997

[4] Heath, A Morris (2007). Advanced Modeling for Small Glass Furnaces. Master's Thesis, West Virginia University, On-line Abstract

Available: https://eidr.wvu.edu/files/5066/Morris_Heath_thesis.pdf

[5] Tooley, Fay V. The Handbook of Glass Manufacture,V. 2, 3ed, Ashlee Publishing Co. Inc., New York, NY, 1984. ISBN 0-911993-21-5.

[6] Pot Furnace, http://www.eisch.de/de/website/virtualroundtrip/Schmelzer_einlegen.jpg (Last Accessed 11/04/2007)

[7] Akron Marbles, http://akronmarbles.com/how_marbles_are_made.htm (Last Accessed 11/04/2007)

[8] Collector's Guide to Marbles: http://www.cowtowncollectibles.com/Collectors\%20Guide\%20to\%20Marbles.html (Last Accessed 4/14/2008)

[9] LandOfMarbles.com, http://www.landofmarbles.com/archive/archive.php?id=265 (Last Accessed 11/04/2007)

[10] Cost Estimation: an expert-opinion approach / Charles Buffalano, Stephen Fogleman, and Mark Gielecki; Goddard Space Flight Center, Greenbelt, Md.

[11] 2002 AACE International Transactions, EST.02.1, Cost Estimating Best Practices, Allen C. Hamilton, CCE, and Richard E. Westney, P.E.

[12] TWI Ltd, http://www.twi.co.uk/j32k/protected/band_3/ksjw001.html (Last Accessed 11/04/2007)

[13] Maskell, Brian H. "SOLVING THE STANDARD COST PROBLEM.” Journal of Cost Management; 20, no.1. (Jan/Feb 2006). ABI/INFORM Global, pg. 27 
[14] Journal of Cost Management. http://www.corbett.pro.br/taxabc.pdf (Last Accessed 11/04/2007)

[15] Wonderful West Virginia. http://www.wonderfulwv.com/sub.cfm?month=sept07\&fea=2 (Last Accessed 11/04/2007)

[16] The British Glass Website. http://www.britglass.org.uk/AboutGlass/GlassForming.html (Last Accessed 11/04/2007)

[17] Devellion Limited. http://www.weberglass.com/index.php?act=viewDoc\&docId=17 (Last Accessed 11/04/2007)

[18] eNotes.com, Inc. http://www.enotes.com/how-products-encyclopedia/marbles (Last Accessed 11/04/2007)

[19] http://strategis.ic.gc.ca/canadian_industry_statistics/cis.nsf/IDE/cis32721cste.html (Last Accessed 04/27/2008)

[20] Clean Washington Center. http://www.cwc.org/glass/gl_htm/g1963rpt.htm\# (Last Accessed 11/04/2007)

[21] O'Guin, Michael C. The Complete Guide to Activity Based Costing. New Jersey: Prentice Hall, 1991.

[22] National Marbles Tournament Inc. http://www.nationalmarblestournament.org (Last Accessed 04/13/2008) 


\section{APPENDIX}

\section{Instructions Manual for the Model}

- When the model is opened, the welcome screen with a button on the top that says "start of the program" is seen. On click of the button, the screen is directed toward another screen.

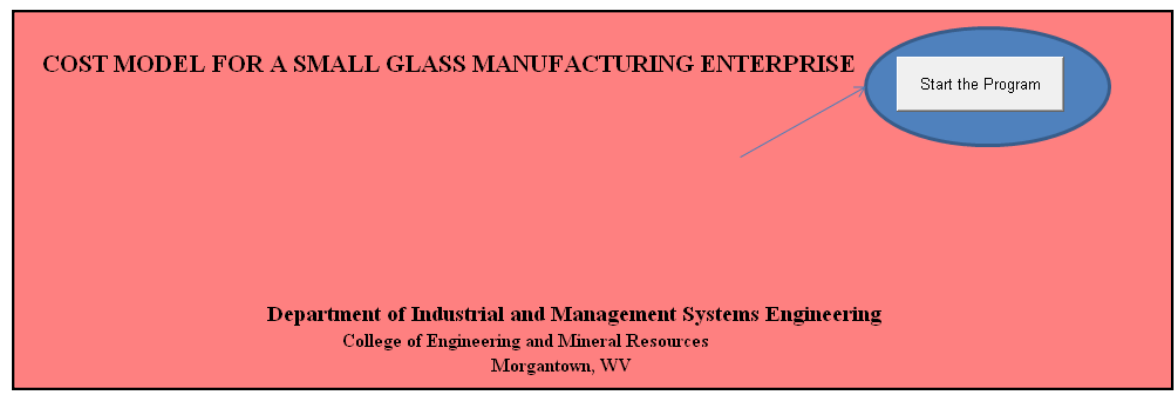

Figure A.1. Start of the Model.

- The next screen has two buttons, "open data forms" and "cost estimating form".

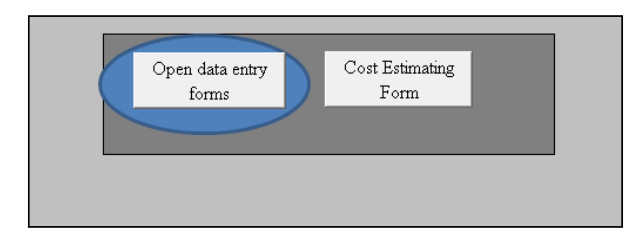

Figure A.2. Open data forms.

- The click of "open data forms" directs a screen with four buttons: material input, other inputs, display results and close window.

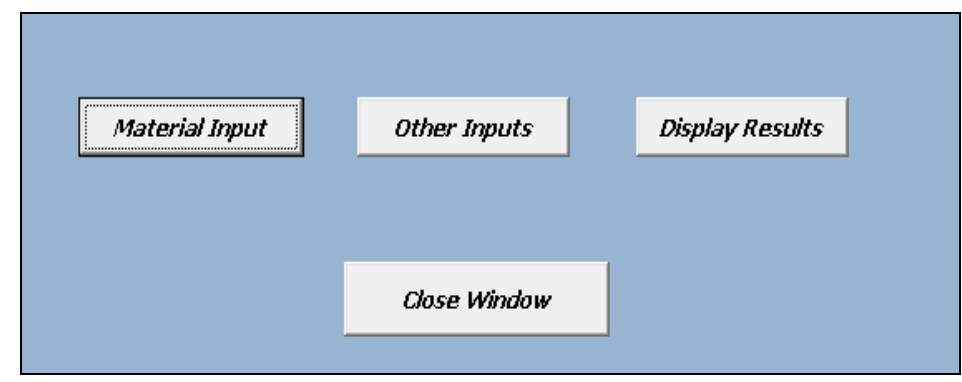

Figure A.3. Buttons for data forms.

- "Material input" on click opens a user data form that has raw materials, mix ratios of raw materials $(\%)$, and the unit costs $(\$ / 1 b)$. The user has to input the mix ratios for different 
materials and their corresponding unit costs. The percentage of mix ratio should be entered in the form of decimals (for example, if it is $8 \%$, then it should be entered as .08). The user after the addition of inputs has to click on "add record" button and the records entered by the user will be fed to the sheet.

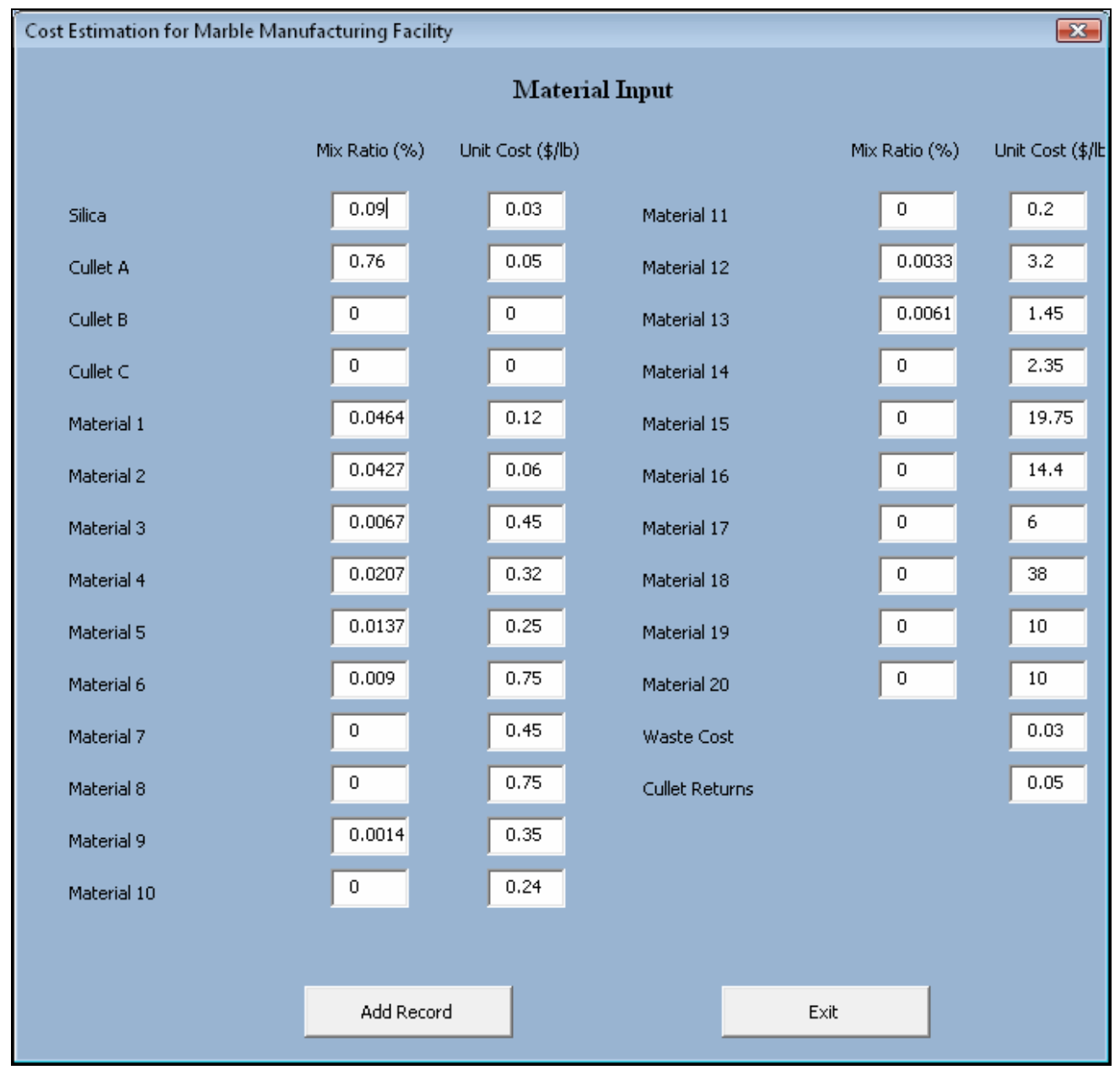

Figure A.4. Material Input User Form.

- The user has to close the material input form and open the "other inputs" by clicking on it. The data needs to be entered and "add record" button should be clicked. The other input contains the product description data, energy data, utilities data, labor data, and the expenses data. The exit button on the other inputs form closes the form. 


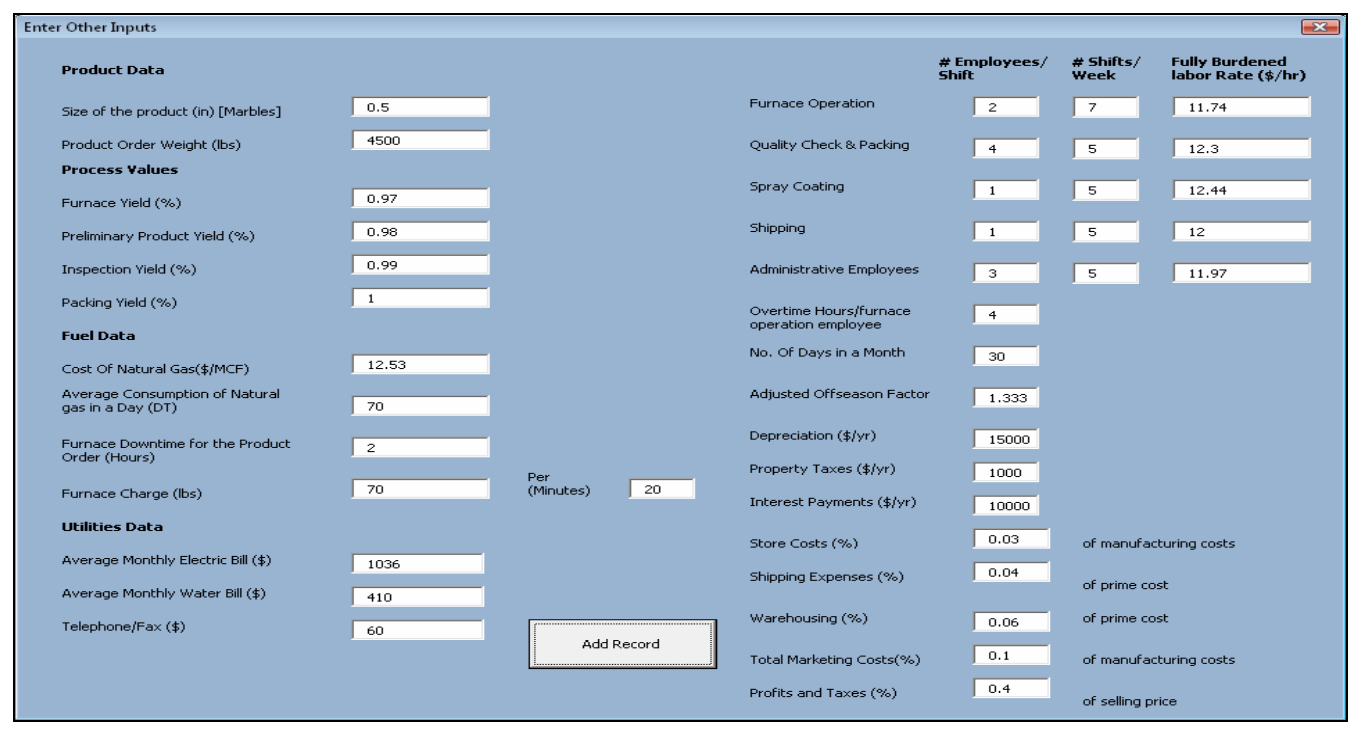

Figure A.5. Other Inputs User Form.

- The screen with four buttons will be seen after closing the other inputs form, and then the "display results" button should be clicked. It directs to another screen that shows results of the cost model.

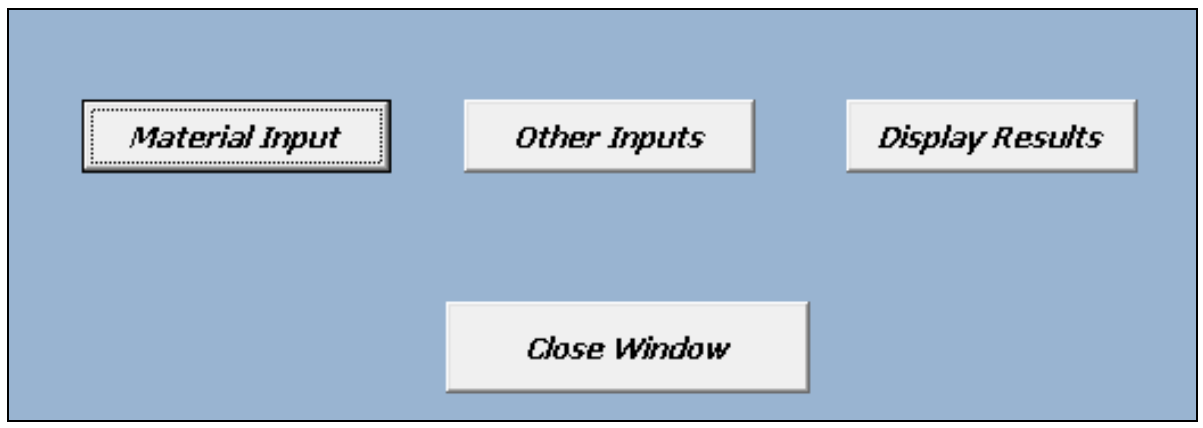

Figure A.6. Screen with display results button.

- The results screen has unit material cost for the product order $(\$ / \mathrm{lb})$, total material cost of the product order $(\$)$, unit natural gas cost per pound of product order, direct material cost $(\$ / \mathrm{lb})$, utilities cost $(\$ / \mathrm{lb})$, selling expenses, total costs, profits and taxes, and unit selling price.

- In the results screen, there is a button which says "go back" to open the user forms screen. 
Table A.1. Summary Cost Output Form.

\begin{tabular}{|l|c|c|}
\hline OUTPUT - Red Marble & $\mathbf{( \$ / l b )}$ & $\begin{array}{c}\text { Total Costs/Product } \\
\text { Order }\end{array}$ \\
\hline Unit Material Cost after yield & $\$ 0.0922$ & $\$ 415.02$ \\
\hline & & \\
\hline Unit Natural gas cost & $\$ 0.1903$ & $\$ 856.22$ \\
\hline Unit direct labor cost & $\$ 0.1508$ & $\$ 1,245$ \\
\hline & & \\
\hline Unit utilities cost & $\$ 0.0127$ & $\$ 47.63$ \\
\hline & & \\
\hline Unit selling expenses & $\$ 0.1535$ & $\$ 690.83$ \\
\hline & & \\
\hline Unit total cost & $\$ 0.7501$ & $\$ 3,897.15$ \\
\hline & & \\
\hline Profits \& Taxes & & $\$ 1,670.21$ \\
\hline & & \\
\hline Unit selling price & $\$ 1.237$ & \\
\hline
\end{tabular}

- The cost estimating form button on the screen on click opens a sheet that has a detailed explanation of the costs.

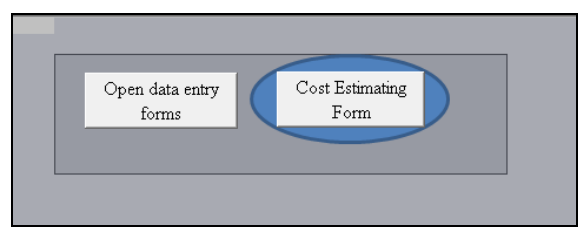

\section{Figure A.7. Open Cost Estimating Form.}

- Labor cost, material cost, indirect costs, administrative expenses, and selling expenses include marketing costs, warehouse costs, and selling costs. The unit selling price of the product is also shown in the cost estimating form, and this is the end of the cost model. 
Table A.2. Detailed Estimation.

\begin{tabular}{|c|c|c|c|c|c|c|c|c|c|}
\hline \multicolumn{9}{|c|}{ Detailed form for Red Marble } & \multirow{2}{*}{$\begin{array}{c}\text { Percent } \\
\text { of Total } \\
\text { Costs }\end{array}$} \\
\hline \multicolumn{9}{|c|}{ Manufacturing/Factorv Cost } & \\
\hline \multicolumn{2}{|c|}{ Prime Costs } & & & & & & & & \\
\hline Direct labor & Hours & Rates & Shifts & Cost/Product & $\$ / l b$ & Total Cost & \$/month & & \\
\hline Furnace Operation & 22.77 & $\$ 11.74$ & 1.90 & $\$ 713$ & $\$ 0.151$ & & $\$ 17.107$ & & \\
\hline OualitvCheck\& & 5.42 & $\$ 12.30$ & 0.45 & $\$ 356$ & $\$ 0.035$ & & $\$ 11.108$ & & \\
\hline Sprav Coating & 5.42 & $\$ 12.44$ & 0.45 & $\$ 90$ & $\$ 0.025$ & & $\$ 2.986$ & & \\
\hline Shipping & 5.42 & $\$ 12.00$ & 0.45 & $\$ 87$ & $\$ 0.024$ & & $\$ 2.880$ & & \\
\hline Direct Supervision & & $0 \%$ & \multicolumn{2}{|c|}{ of direct labor } & & $\$ 0.00$ & & & \\
\hline Direct Labor Cost & & & & & & $\$ 1.245$ & $\$ 46.362$ & & $31.94 \%$ \\
\hline Direct Materials & wt/unit) & Rates & & Cost/Product & & & & & \\
\hline Silica & 430.35 & $\$ 0.03$ & & $\$ 12.91$ & & & & & \\
\hline Cullet A & 3634.07 & $\$ 0.05$ & & $\$ 181.70$ & & & & & \\
\hline Cullet B & 0.00 & $\$ 0.00$ & & $\$ 0.00$ & & & & & \\
\hline Cullet C & 0.00 & $\$ 0.00$ & & $\$ 0.00$ & & & & & \\
\hline Material 1 & 221.87 & $\$ 0.12$ & & $\$ 26.62$ & & & & & \\
\hline Material 2 & 204.18 & $\$ 0.06$ & & $\$ 12.25$ & & & & & \\
\hline Material 3 & 32.04 & $\$ 0.45$ & & $\$ 14.42$ & & & & & \\
\hline Material 4 & 98.98 & $\$ 0.32$ & & $\$ 31.67$ & & & & & \\
\hline Material 5 & 65.51 & $\$ 0.25$ & & $\$ 16.38$ & & & & & \\
\hline Material 6 & 43.04 & $\$ 0.75$ & & $\$ 32.28$ & & & & & \\
\hline Material 7 & 0.00 & $\$ 0.45$ & & $\$ 0.00$ & & & & & \\
\hline Material 8 & 0.00 & $\$ 0.75$ & & $\$ 0.00$ & & & & & \\
\hline Material 9 & 6.69 & $\$ 0.35$ & & $\$ 2.34$ & & & & & \\
\hline Material 10 & 0.00 & $\$ 0.24$ & & $\$ 0.00$ & & & & & \\
\hline Material 11 & 0.00 & $\$ 0.20$ & & $\$ 0.00$ & & & & & \\
\hline Material 12 & 15.78 & $\$ 3.20$ & & $\$ 50.49$ & & & & & \\
\hline Material 13 & 29.17 & $\$ 1.45$ & & $\$ 42.29$ & & & & & \\
\hline Material 14 & 0.00 & $\$ 2.35$ & & $\$ 0.00$ & & & & & \\
\hline Material 15 & 0.00 & $\$ 19.75$ & & $\$ 0.00$ & & & & & \\
\hline Material 16 & 0.00 & $\$ 14.40$ & & $\$ 0.00$ & & & & & \\
\hline Material 17 & 0.00 & $\$ 6.00$ & & $\$ 0.00$ & & & & & \\
\hline Material 18 & 0.00 & $\$ 38.00$ & & $\$ 0.00$ & & & & & \\
\hline Material 19 & 0.00 & $\$ 10.00$ & & $\$ 0.00$ & & & & & \\
\hline Material 20 & 0.00 & $\$ 10.00$ & & $\$ 0.00$ & & & & & \\
\hline Waste Cost & 71.73 & $\$ 0.03$ & & $\$ 2.15$ & & & & & \\
\hline Cullet Returns & 209.94 & $\$ 0.05$ & & $(\$ 10.50)$ & $\$ / 1 b$ & & & & \\
\hline Direct Material Cost & & & & & $\$ 0.092$ & $\$ 415.02$ & & & $(10.65) \%$ \\
\hline & \$/DT & DT/Orde & & Cost/Product & $\$ / 1 \mathrm{~b}$ & & & & \\
\hline Melting Costs & $\$ 12.53$ & 68.33 & & $\$ 856.22$ & $\$ 0.19$ & $\$ 856.22$ & & & $(21.97) \%$ \\
\hline Manufacturing & Amountt & Rate & Batch & Total Cost & & & & & \\
\hline Tooling & 1 Set & $\$ 3.000$ & 600 & $\$ 15.00$ & & $\$ 15.00$ & & & \\
\hline & & \$/vear & & \$/Pound & & & \$/month & & \\
\hline Depreciation & & $\$ 15.000$ & & $\$ 0.074$ & & $\$ 188.32$ & $\$ 1.250$ & & $11.13 \%$ \\
\hline Property Taxes & & $\$ 10,000$ & & $\$ 0.050$ & & $\$ 223.21$ & $\$ 833$ & & \\
\hline Interest Pavment & & $\$ 1.000$ & & $\$ 0.005$ & & $\$ 22.32$ & $\$ 83$ & & \\
\hline Total Prime Cost & & & & & & & & $\$ 2.965$ & $76.08 \%$ \\
\hline Indirect Materials & & $5 \%$ & \multicolumn{2}{|c|}{ of direct materials } & & $\$ 20.75$ & & & \\
\hline \multirow[t]{2}{*}{ Utilities } & & & & & & & & & \\
\hline & \$/Month & \$/Batch & & & $\$ / 1 b$ & & & & \\
\hline Electricity & $\$ 1.036 .0$ & $\$ 0.480$ & & & $\$ 0.01$ & & & & \\
\hline Water & $\$ 410$ & $\$ 0.190$ & & & $\$ 0.002$ & & & & \\
\hline Telephone/Fax & $\$ 60.0$ & $\$ 0.028$ & & & $\$ 0.000$ & & & & \\
\hline & $\$ 1.446 .0$ & $\$ 0.697$ & & & $\$ 0.013$ & $\$ 47.63$ & & & \\
\hline Total Indirect Costs & & & & & & & & & $1.75 \%$ \\
\hline Mfg Cost & & & & & & & & $\$ 3.033$ & $77.83 \%$ \\
\hline Plant Administrative & & Rate & \# shifts & $\$ /$ Order & $\$ / 1 b$ & & \$/month & & \\
\hline Administrative & & $\$ 11.97$ & 0.45 & $\$ 173.01$ & $\$ 0.07$ & & $\$ 11.488 .3$ & & \\
\hline Administrative $\mathrm{t}$ & & & & & & $\$ 173.01$ & & & $4.44 \%$ \\
\hline Production Costs & & & & & & & & $\$ 3.206$ & $82.27 \%$ \\
\hline Selling Expenses & & & & & $\$ / 1 b$ & & & & \\
\hline Store Costs & & $3 \%$ & of manu & ring costs & $\$ 0.021$ & $\$ 91.00$ & & & \\
\hline Shipping Expenses & & $4 \%$ & of prim & & $\$ 0.028$ & $\$ 118.6$ & & & \\
\hline Warehousing & & $6 \%$ & of prim & & $\$ 0.041$ & $\$ 177.9$ & & & \\
\hline Total Marketing & & $10 \%$ & of manu & ring costs & $\$ 0.070$ & $\$ 303.33$ & & & \\
\hline & & & & & & $\$ 690.8$ & & & $17.7 \%$ \\
\hline Total Costs & & & & & & & & $\$ 3.897$ & $100.00 \%$ \\
\hline Mark - up & & & & & & & & & \\
\hline Profit and Taxes & & $30 \%$ & of Sellii & & & $\$ 1.670 .21$ & & & \\
\hline Selling Price & & & & & & $\$ 5.567$ & & $\$ 5.567$ & \\
\hline Unit Selling Price-\$/1 & & & & & $\$ 1.24$ & & & & \\
\hline
\end{tabular}

